\title{
Precision mouse models with expanded tropism for human pathogens
}

\author{
Angela Wahl ${ }^{1 \star}$, Chandrav $\mathrm{De}^{1,10}$, Maria Abad Fernandez ${ }^{2,10}$, Erik M. Lenarcic ${ }^{2,3}$, Yinyan $\mathrm{Xu}^{2}$, \\ Adam S. Cockrell ${ }^{4}$, Rachel A. Cleary', Claire E. Johnson ${ }^{1}{ }^{1}$, Nathaniel J. Schramm', Laura M. Rank ${ }^{2}$, \\ Isabel G. Newsome ${ }^{5}$, Heather A. Vincent ${ }^{2,3}$, Wes Sanders ${ }^{2,3}$, Christian R. Aguilera-Sandoval ${ }^{1,9}$, \\ Allison Boone ${ }^{2,6}$, William H. Hildebrand ${ }^{7}$, Paul A. Dayton ${ }^{5}$, Ralph S. Baric ${ }^{2,4}$, Raymond J. Pickles ${ }^{2,6}$, \\ Miriam Braunstein ${ }^{2}$, Nathaniel J. Moorman ${ }^{2,3}$, Nilu Goonetilleke ${ }^{2,8}$ and J. Victor Garcia ${ }^{1 *}$
}

\begin{abstract}
A major limitation of current humanized mouse models is that they primarily enable the analysis of human-specific pathogens that infect hematopoietic cells. However, most human pathogens target other cell types, including epithelial, endothelial and mesenchymal cells. Here, we show that implantation of human lung tissue, which contains up to $\mathbf{4 0}$ cell types, including nonhematopoietic cells, into immunodeficient mice (lung-only mice) resulted in the development of a highly vascularized lung implant. We demonstrate that emerging and clinically relevant human pathogens such as Middle East respiratory syndrome coronavirus, Zika virus, respiratory syncytial virus and cytomegalovirus replicate in vivo in these lung implants. When incorporated into bone marrow/liver/thymus humanized mice, lung implants are repopulated with autologous human hematopoietic cells. We show robust antigen-specific humoral and T-cell responses following cytomegalovirus infection that control virus replication. Lung-only mice and bone marrow/liver/thymus-lung humanized mice substantially increase the number of human pathogens that can be studied in vivo, facilitating the in vivo testing of therapeutics.
\end{abstract}

A lthough in vivo animal models exist for many clinically relevant and emerging human pathogens ${ }^{1-4}$, they currently all lack biologically relevant human cells, which limits our ability to study pathogen replication, pathogenesis, immune responses and sensitivity to therapeutics in vivo. In vivo animal models with natural human target cells for infection are needed to accelerate the development and testing of effective vaccines and therapeutics for many highly relevant human pathogens such as human cytomegalovirus (HCMV), human respiratory syncytial virus (RSV) and Mycobacterium tuberculosis, in addition to many emerging pathogens $^{1}$, all of which cause substantial global mortality and morbidity ${ }^{5-9}$.

Although commonly used, inbred mouse strains do not faithfully recapitulate important aspects of human disease and the human immune response ${ }^{10}$. Furthermore, many human pathogens do not replicate in wild-type mice ${ }^{1,5,11-21}$. The availability of highly immunodeficient mouse strains allows for the creation of human/ mouse chimeric models (humanized mice) that are locally or systemically reconstituted with human hematopoietic cells following engraftment of human tissues and/or stem cells. Humanized mice have been used to study human immune development and human-specific pathogens that replicate in human hematopoietic cells (for example, Epstein-Barr virus, dengue virus, human immunodeficiency virus, Kaposi's sarcoma herpesvirus) and to test the efficacy of preventative and therapeutic agents ${ }^{5,11-19,22,23}$. Bone marrow/liver/thymus (BLT) humanized mice are generated by bone marrow transplantation of immunodeficient mice implanted with autologous human thymus/liver tissue. BLT mice are systemically reconstituted with human innate (monocytes/macrophages, dendritic cells, natural killer (NK) cells) and adaptive (B and T cells) immune cells. The presence of a human thymic organoid in the BLT model allows for human T-cell education on human leukocyte antigens (HLA) and the induction of HLA-restricted T-cell responses consistent with those observed in humans ${ }^{14,24,25}$.

The applications of current humanized mouse models for biomedical research would be significantly broadened by the inclusion of human nonhematopoietic cell types, the primary targets of most human pathogens, which can present antigen to autologous human immune cells in the full context of HLA H, $^{5,26-29}$. The human lung contains up to 40 different cell types including epithelial, endothelial, mesenchymal and smooth muscle cells $\mathrm{s}^{30}$ and it is an important natural site of pathogen replication ${ }^{9,26,31-34}$. We implanted human lung tissue subcutaneously into the back of immunodeficient mice to create humanized lung-only mice (LoM). The human lung tissue vascularizes, expands and persists as a human lung implant, and supports replication of viral and bacterial human pathogens in vivo. When incorporated into BLT mice (BLT-lung (BLT-L) mice), lung implants are repopulated with autologous human innate and adaptive immune cells. Direct inoculation of BLT-L human lung implants with HCMV induces HCMV-specific human IgM, IgG and T-cell responses which can effectively control infection

'Division of Infectious Diseases, International Center for the Advancement of Translational Science, Center for AIDS Research, University of North Carolina, School of Medicine, Chapel Hill, NC, USA. ²Department of Microbiology and Immunology, University of North Carolina, Chapel Hill, NC, USA. ${ }^{3}$ Lineberger Comprehensive Cancer Center, University of North Carolina, Chapel Hill, NC, USA. ${ }^{4}$ Department of Epidemiology, University of North Carolina, Chapel Hill, NC, USA. ${ }^{5}$ Joint Department of Biomedical Engineering, University of North Carolina and North Carolina State University, Chapel Hill, NC, USA. ${ }^{6}$ Marsico Lung Institute, University of North Carolina, Chapel Hill, NC, USA. ${ }^{7}$ Department of Microbiology and Immunology, University of Oklahoma Health Sciences Center, Oklahoma City, OK, USA. ${ }^{8}$ UNC HIV Cure Center, University of North Carolina, Chapel Hill, NC, USA. 9Present address: BD Life Sciences, San Jose, CA, USA. ${ }^{10}$ These authors contributed equally: Chandrav De, Maria Abad Fernandez. *e-mail: angela_wahl@med.unc.edu; victor_garcia@med.unc.edu 
in vivo. LoM and BLT-L mice expand the susceptibility of humanized mice to a broad range of human pathogens. These models can be used to study pathogen replication, pathogenesis, immune reactivity and human therapies.

\section{Results}

Human lung tissue development into ectopic lung implants. Two small pieces of human lung tissue were surgically implanted into separate sites on the back of immunodeficient mice to create humanized LoM. Over time, the implanted tissue expanded (Fig. 1a). B-mode ultrasound imaging established the presence of well-defined implants with a mean volume of $0.75 \mathrm{~cm}^{3}\left( \pm 0.42 \mathrm{~cm}^{3}\right)$ (Fig. 1b,c). Acoustic angiography ${ }^{35,36}$ revealed angiogenesis and the formation of large blood vessels (Fig. 1d, left panel). Vasculature was also observed within the human lung implant (Fig. 1d, right panel). Figure 1e and Supplementary Video 1 show a three-dimensional (3D) reconstruction of the implant, illustrating its structure and extensive vasculature. Finally, surgical excision of a human lung implant revealed its well-defined structure and internal vasculature (Fig. 1f).

Even though the lung implants are ectopic and not ventilated, we observed structures that are characteristic of the human lung including airways, ciliated epithelium, alveolar structures, cartilage and associated blood vessels (Fig. 1g). We observed cartilaginous bronchial and noncartilaginous bronchiolar airways, both of which were lined by ciliated airway epithelium (Fig. 1g). Pre-alveolar sacs were also present (Fig. 1g). The presence of human epithelial, endothelial and mesenchymal cells was also confirmed (Fig. 1h,i). Club cells and nonciliated secretory epithelial cells were also present (Fig. 1j). Staining for mucus secretions revealed the presence of mucin-secreting human globlet epithelial cells (Fig. 1k). Ex vivo culture of lung implant cells with lipopolysaccharide (LPS) demonstrated their capacity to produce human cytokines and chemokines (Supplementary Table 1).

Analysis of human donor matched lung tissue at the time of implantation and at 2 months postimplantation indicates continuous human lung tissue development. Pre-alveolar sacs were expanded and both flattened and cuboidal-shaped epithelial cells could be observed in alveoli, indicative of type I and type II pneumocytes, respectively (Supplementary Fig. 1). Although not observed in lung tissue at the time of implantation, club cells were readily detected 2 months later (Fig. 1j and Supplementary Fig. 1) and ciliated epithelial cells were more abundant (Supplementary Fig. 1).

Consistent with reports of other subcutaneously implanted human tissues (for example, synovial tissue and bone) ${ }^{37,38}$, the vasculature within the human lung implants is primarily of human origin (Fig. 1h). Mouse endothelial and epithelial cells were not readily detected (Supplementary Fig. 2). Few hematopoietic cells (murine or human) could be detected in human lung implants (Supplementary Figs. 2 and 3). In summary, implantation of human lung tissue into the back of immunodeficient mice results in the development of well-defined, well-vascularized and easily accessible human lung implants with structures that resemble those present in human lung tissue and that are composed almost entirely of human cells.

LoM support infection of a broad range of human pathogens. Middle East respiratory syndrome coronavirus (MERS-CoV) is an emerging human pathogen that targets the human lung ${ }^{26}$ but which does not infect mice, ferrets or hamsters due to genetic differences in its receptor, dipeptidyl peptidase 4 (DPP4) $)^{1,20,21}$. MERS-CoV was inoculated directly into the human lung implants of LoM. MERS$\mathrm{CoV}$ titers (mean $2.02 \times 10^{8} \pm 1.08 \times 10^{8}$ s.e.m. plaque-forming units (PFU) $\mathrm{ml}^{-1} \mathrm{~g}^{-1 ;}$ range $1.2 \times 10^{6}-8.09 \times 10^{8} \mathrm{PFU} \mathrm{ml}^{-1} \mathrm{~g}^{-1}$ ) in the human lung implants $48 \mathrm{~h}$ later were 3 logs higher than the inoculum (Fig. 2a). The presence of MERS-CoV antigen in human epithelial, endothelial and mesenchymal cells indicated that MERS-CoV has broad cellular tropism in vivo (Fig. 2b). At a lower inoculum $\left(10^{4} \mathrm{PFU}\right)$, MERS-CoV replication was variable but still readily detectable (mean $2.29 \times 10^{8} \pm 2.09 \times 10^{8}$ s.e.m. $P F U m^{-1} \mathrm{~g}^{-1}$; range $\left.1.92 \times 10^{3}-8.57 \times 10^{8} \mathrm{PFU} \mathrm{m} \mathrm{m}^{-1} \mathrm{~g}^{-1}\right)$ (Fig. 2a).

Zika virus (ZIKV) has been detected in human neonatal lungs and shown to infect human lung cell lines in vitro ${ }^{31,39}$. In wild-type mice, the type 1 interferon response suppresses ZIKV infection ${ }^{2}$. Human lung implants of LoM inoculated with ZIKV and assayed $48 \mathrm{~h}$ later contained robust levels of cell-associated ZIKV RNA (mean $1.37 \times 10^{4} \pm 5.91 \times 10^{3}$ s.e.m. ZIKV RNA copies per $10^{5}$ cells; range $5.21 \times 10^{3}-2.42 \times 10^{4}$ ZIKV RNA copies per $10^{5}$ cells) (Fig. $2 \mathrm{c}$ ). ZIKV antigen was detected in human epithelial and mesenchymal cells (Fig. 2d). Similar to MERS-CoV, at a lower inoculum $\left(10^{3}\right.$ focus-forming units (FFU)), ZIKV RNA levels were variable but readily detectable (mean $2.65 \times 10^{3} \pm 1.47 \times 10^{3}$ s.e.m. ZIKV RNA copies per $10^{5}$ cells; range $2.7 \times 10^{1}-6.83 \times 10^{3}$ ZIKV RNA copies per $10^{5}$ cells) (Fig. $2 \mathrm{c}$ ).

We inoculated Mycobacterium bovis Bacillus Calmette-Guérin (BCG), the attenuated live vaccine strain of M. tuberculosis, into the human lung implants of LoM. Bacterial burden was assessed by colony formation (colony forming units, c.f.u.). BCG levels in human lung implants of LoM $28 \mathrm{~d}$ postexposure (mean $3.40 \times 10^{5} \pm 1.20 \times 10^{5}$ s.e.m. c.f.u.; range $1.03 \times 10^{5}-4.95 \times 10^{5}$ c.f.u.) were 8.5 -fold higher than the inoculum $\left(4 \times 10^{4}\right.$ c.f.u. $)$ (Fig. 2e). BCG also replicated in the human lung implants of LoM receiving a 100 -fold lower inoculum $\left(4 \times 10^{2}\right.$ c.f.u. $)$; the bacterial burden (mean $2.57 \times 10^{4} \pm 1.53 \times 10^{4}$ s.e.m. c.f.u.; range $3.10 \times 10^{3}-$ $5.49 \times 10^{4}$ c.f.u.) was 65 -fold higher than the inoculum. Acid-fast staining confirmed diffuse clusters of bacteria within the human lung implants (Fig. 2f).

We inoculated LoM implants with RSV expressing green fluorescent protein (GFP). At $4 \mathrm{~d}$ post-RSV inoculation, GFP-positive cells indicative of RSV infection and replication were detected in the human lung implants (mean $144.38 \pm 41.53$ s.e.m. $\mathrm{GFP}^{+}$cells per $10^{5}$ total cells; range $35-333 \mathrm{GFP}^{+}$cells per $10^{5}$ total cells) (Fig. 2g). Infection of human airway epithelial cells in vitro and in vivo with RSV is characterized by extrusion of infected cells into the airway lumen and loss of cilia from infected ciliated cells ${ }^{40}$. Consistent with these observations, RSV-infected cells were observed protruding and shedding from the epithelial cell layer into the lumen (Fig. 2h) and they lacked costaining for cilia (Fig. 2i). Large deposits of mucin were also noted in the airways of RSV-infected lung implants (Fig. $2 \mathrm{j}$ ) as has been observed in the lungs of RSV-infected children ${ }^{41}$.

HCMV is a ubiquitous human-specific pathogen that does not replicate in other species ${ }^{5}$. We injected cell-free HCMV TB40/E, a clinical HCMV strain, into the human lung implants of LoM. HCMV DNA was detected in the lung implants of LoM as early as $4 \mathrm{~d}$ postinoculation (mean $4.70 \times 10^{3} \pm 2.54 \times 10^{3}$ s.e.m. HCMV DNA copies per $10^{5}$ cells; range $2.94 \times 10^{2}-1.19 \times 10^{4} \mathrm{HCMV}$ DNA copies per $10^{5}$ cells) (Fig. 2k). HCMV immediate early (IE), early and late proteins were detected in lung implants at $14 \mathrm{~d}$ and $52 \mathrm{~d}$ postinoculation indicating that HCMV infection was maintained over time (Fig. 2l). The expression of IE proteins is consistent with lytic HCMV replication in this model as observed during human primary infection and reactivation ${ }^{42}$. In vivo, HCMV antigen was observed in human mesenchymal cells (Fig. $2 \mathrm{~m}$ ). We determined the effect of preexposure prophylaxis with ganciclovir (GCV) on HCMV replication in LoM. GCV was administered once daily $2 \mathrm{~d}$ before and $14 \mathrm{~d}$ after inoculation of HCMV TB40/E expressing luciferase (Fig. 2n). HCMV replication was monitored over time by measuring luciferase activity. By $4 \mathrm{~d}$ postexposure, HCMV levels were $\sim 66 \%$ lower in the human lung implants of GCV-treated LoM (mean $3.36 \times 10^{5} \pm 1.61 \times 10^{5}$ s.e.m. radiance) compared with untreated controls (mean $1.00 \times 10^{6} \pm 2.90 \times 10^{5}$ s.e.m. radiance) (Fig. $2 \mathrm{n}$ ). HCMV levels continued to decline over time in GCV-treated LoM. 
a
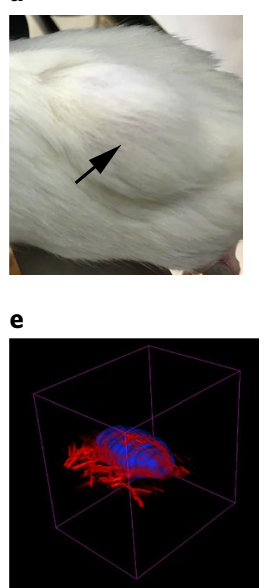

h

h Human lung implant
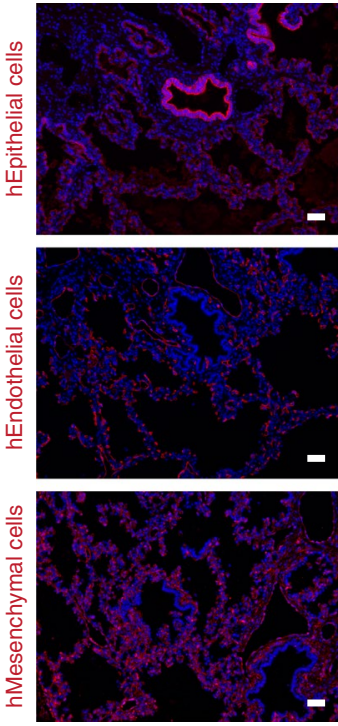

f b
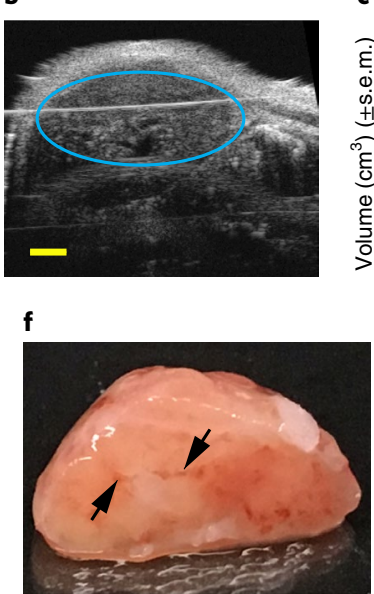

Mouse lung
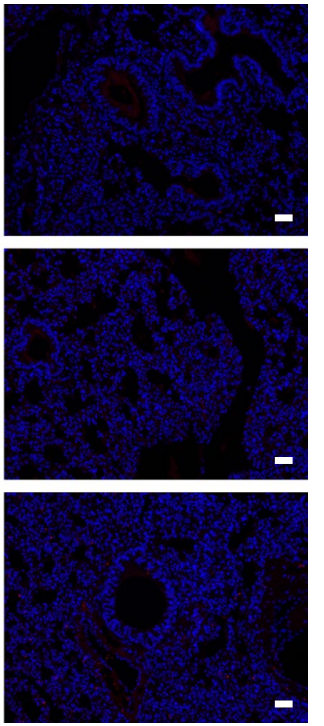

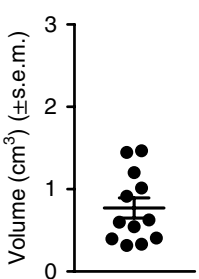

g

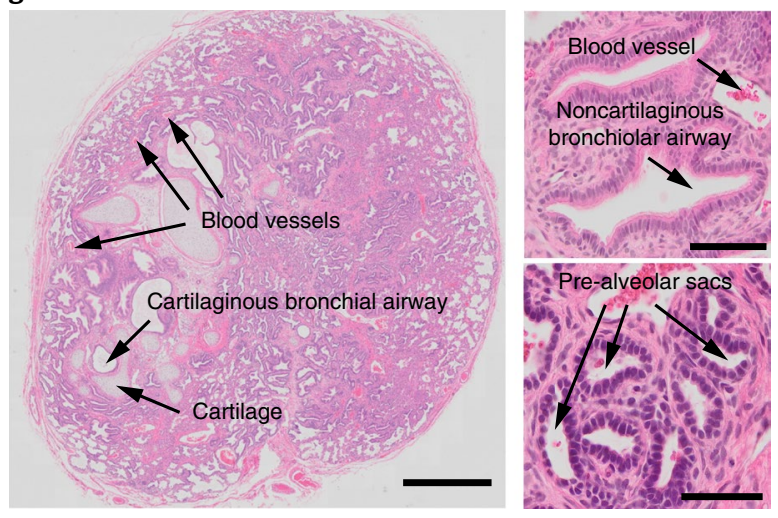

i

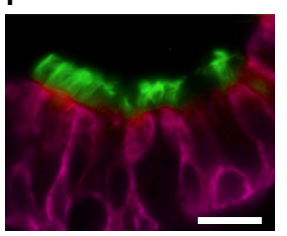

j

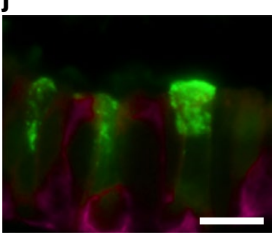

d

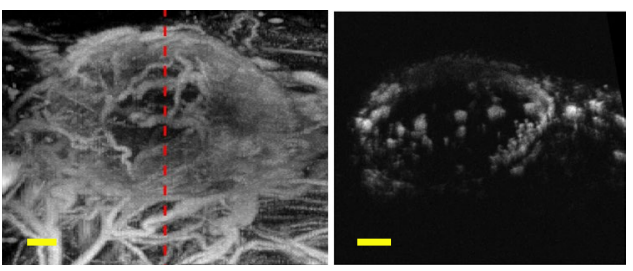

k

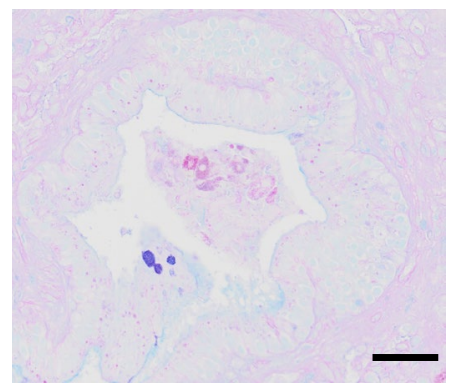

Fig. 1 | Subcutaneous implantation of human lung tissue into immunodeficient mice results in the development of readily accessible ectopic human lung implants. a, Subcutaneous human lung implant ( $n=1$ LoM imaged, black arrow). b, B-mode ultrasound imaging of a human lung implant (blue circle) under the skin. $\mathbf{c}$, Volume ( $\left.\mathrm{cm}^{3}\right)$ of human lung implants ( $n=12$, filled circles) in mice determined from B-mode ultrasound images. d,e, In vivo visualization of human lung implant blood vessel vascularization by acoustic angiography ( $n=12$ implants analyzed). d, Acoustic angiography image showing blood vessels encapsulating (left) and within (right) a human lung implant. A red dashed line (left panel) indicates the location of the implant cross-section depicted in the right panel. e, 3D rendering of vascularization (red) of a human lung implant (blue). f, Gross structure of an excised human lung implant $(n=1) 2$ months postsurgery exhibiting blood vessel vascularization (black arrows). $\mathbf{g}$, Histologic sections of human lung implants ( $n=6$ implants analyzed) showing presence of airways, ciliated epithelium, alveolar structures, cartilage and associated blood vessels (images: top panel, $\times 5$, bottom panels, $\times 100)$. h, Immunofluorescence staining for human epithelial, endothelial and mesenchymal cells in a human lung implant ( $n=3$ implants analyzed, left panels) and mouse lung ( $n=1$ mouse lung analyzed, right panels) (positive cells, red; nuclei, blue). $\mathbf{i}, \mathbf{j}$, Immunofluorescence staining for cytokeratin 19 (magenta) and (i) cilia or (j) club cells (green; scale bars, $20 \mu \mathrm{m}$ ) in a human lung implant ( $n=4$ implants analyzed). k, AB-PAS staining for mucous secretions (blue; scale bars, $20 \mu \mathrm{m}$ ) in a human lung implant ( $n=4$ implants analyzed). In $\mathbf{c}$, horizontal lines represent mean \pm s.e.m. Scales bars in $\mathbf{b}$ and $\mathbf{d}$, $2 \mathrm{~mm}$. In $\mathbf{g}$ and $\mathbf{h}$, scale bars shown for $\times 5(1 \mathrm{~mm}), \times 10(50 \mu \mathrm{m})$ and $\times 100(100 \mu \mathrm{m})$ images. h, human.

At the end of the GCV treatment course (14 d post-HCMV exposure), HCMV levels were $\sim 2$ logs lower in the lung implants of GCV-treated LoM (mean $1.48 \times 10^{5} \pm 4.96 \times 10^{4}$ s.e.m. radiance) compared with untreated LoM (mean $8.99 \times 10^{6} \pm 5.02 \times 10^{6}$ s.e.m. radiance) (Fig. 2n). Surprisingly, after GCV treatment was discontinued, HCMV levels continued to decline. By $25 \mathrm{~d}$ post-HCMV exposure (11 d after the last GCV dose), HCMV levels in the lung implants of GCV-treated LoM were further reduced by 40\% (mean $9.25 \times 10^{4} \pm 2.65 \times 10^{4}$ s.e.m. radiance) and significantly lower than untreated controls (mean $3.27 \times 10^{7} \pm 1.69 \times 10^{7}$ s.e.m. radiance) (Fig. 2n). Together, these results demonstrate the ability of LoM to sustain replication of several clinically relevant human pathogens and to serve as a platform for the in vivo testing of existing and novel antimicrobials.

HCMV gene expression is consistent with lytic replication. In healthy individuals, HCMV establishes a life-long latent infection. In immune-suppressed individuals such as transplant and AIDS patients, HCMV can reactivate, resulting in uncontrolled lytic replication causing a multi-organ cytomegalovirus (CMV) syndrome ${ }^{43}$. Therefore, novel antivirals are needed that can inhibit HCMV lytic replication in vivo to ameliorate clinical symptoms of CMV disease. Since natural infections are typically asymptomatic and undiagnosed, the profile of HCMV genes expressed during lytic replication 


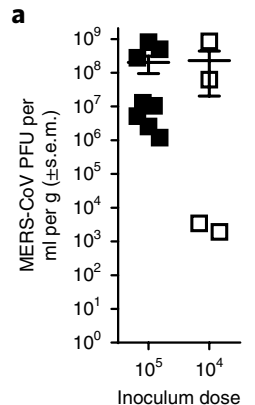

.

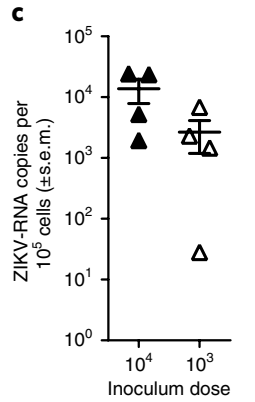

b

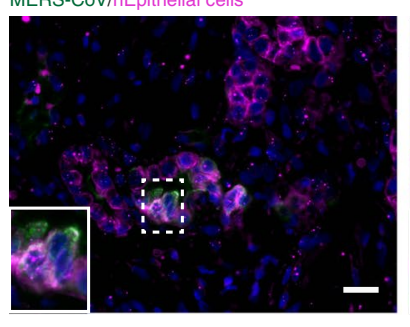

MERS-CoV/hEndothelial cells

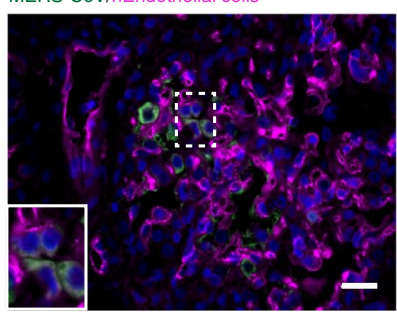

MERS-CoV/hMesenchymal cells

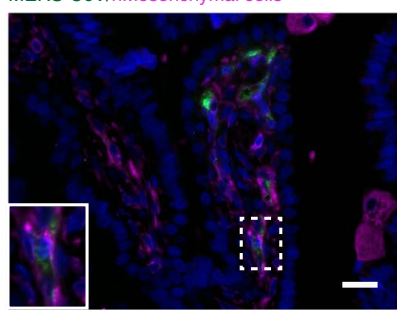

d

ZIKV/hEpithelial cells

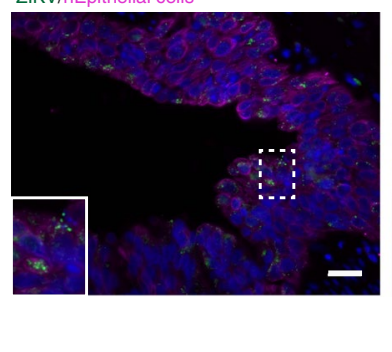

ZIKV/hMesenchymal cells

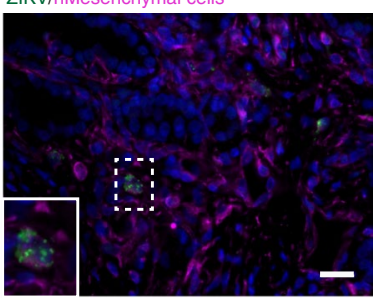

e

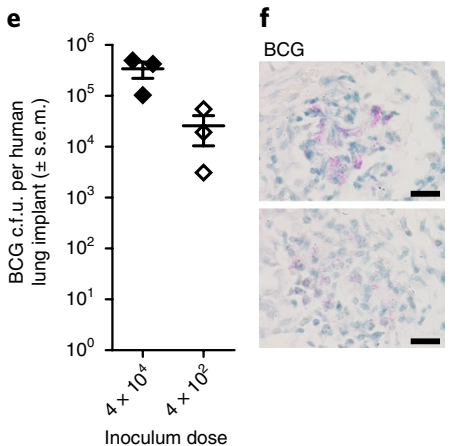

g

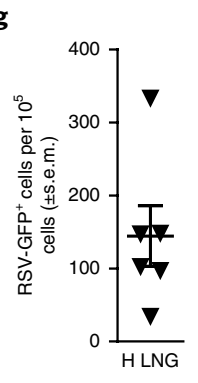

h

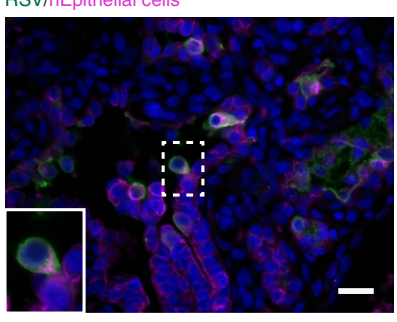

i RSV/Tubulin

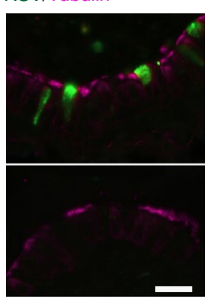

j

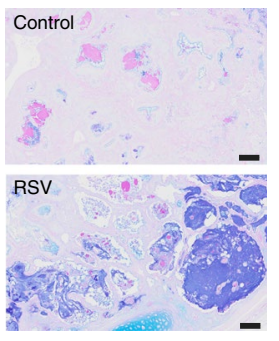

k

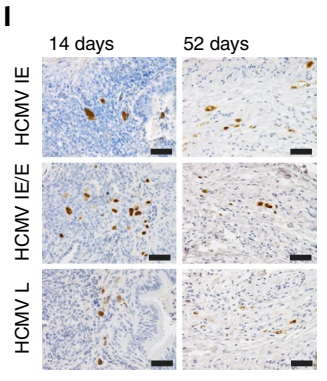

m

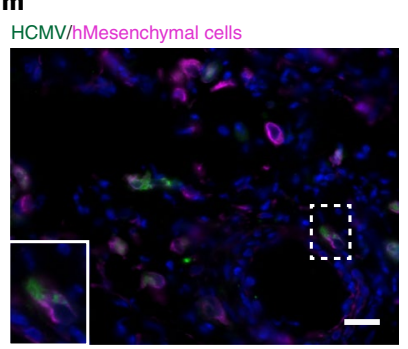

n
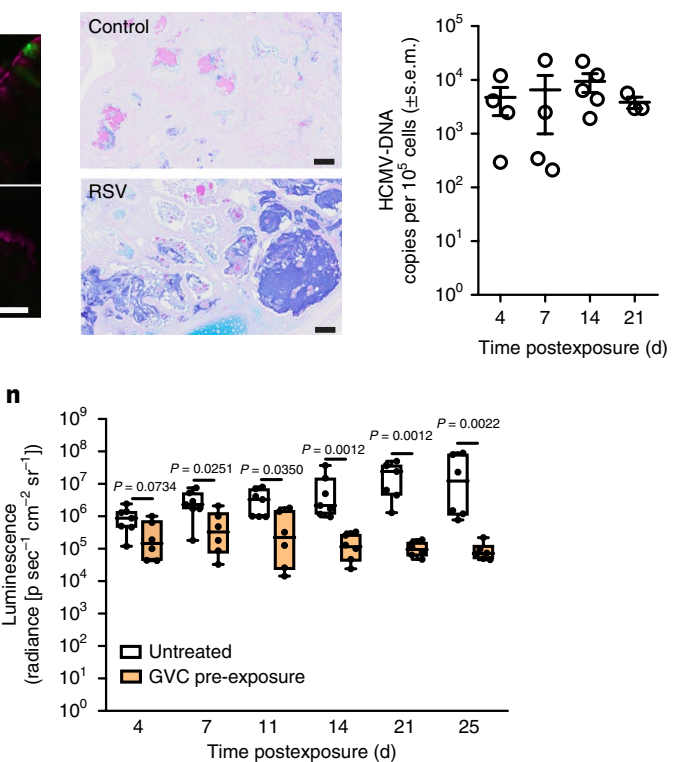

Fig. 2 | LoM are susceptible to infection with a broad range of emerging and clinically relevant human pathogens. a, MERS-CoV titer in infected lung implants ( $10^{5}$ PFU dose: $n=8$, filled squares; $10^{4}$ PFU dose: $n=4$, open squares). b, MERS-CoV-infected cells (green) costained for human epithelial (cytokeratin 19), endothelial (CD34) or mesenchymal (vimentin) cell markers (magenta) in a lung implant ( $n=1$; images, $\times 40$ ). c, ZIKV RNA copies in infected lung implants ( $10^{4} \mathrm{FFU}$ dose: $n=4$, filled upward triangles; $10^{3} \mathrm{FFU}$ dose: $n=4$, open upward triangles). d, ZIKV-infected cells (green) costained for human epithelial or mesenchymal cell markers (magenta) in a lung implant $(n=1$; images, $\times 40)$. e,f, BCG c.f.u. $\left(4 \times 10^{4}\right.$ c.f.u. dose: $n=3$, closed diamonds; $4 \times 10^{2}$ c.f.u. dose: $n=3$, open diamonds) (e) and Ziehl-Neelsen acid-fast staining for BCG (positive, pink) (f) in lung implants ( $n=2$ ). Top and bottom images, $\times 100$. $\mathbf{g}$, Number of RSV-GFP positive cells in lung implants ( $n=6$, closed downward triangles). $\mathbf{h}$, RSV-infected cells (green) costained for a human epithelial cell marker (magenta) in a lung implant ( $n=1$, image, $\times 40)$. i, Costaining for RSV-infected cells (green) and ciliated cells (magenta) (top) and isotype control antibody (green) and ciliated cells (magenta) (bottom panel) in a human lung implant ( $n=4$ analyzed; images, $\times 100)$. j, AB-PAS staining for mucus (blue) in a naïve control ( $n=4$ analyzed, top) and RSV-infected ( $n=4$ analyzed, bottom) lung implant (scale bars, $100 \mu \mathrm{m}$ ). $\mathbf{k}$, HCMV DNA levels (open circles) in lung implants at $4 \mathrm{~d}(n=4), 7 \mathrm{~d}(n=4), 14 \mathrm{~d}(n=5)$ and $21 \mathrm{~d}(n=3)$ post-TB40/E exposure. I, HCMV IE, early (E) and late ( $L$ ) protein expression in lung implants ( $n=1$ per time point; images, $\times 40$; positive cells, brown). $\mathbf{m}, \mathrm{HCMV}$-infected cells (green) costained for a human mesenchymal cell marker (magenta) in a lung implant ( $n=1$; image, $\times 40)$. n, GCV was administered to LoM daily (100 mg kg ${ }^{-1}$ ) for $17 \mathrm{~d}$ starting $2 \mathrm{~d}$ before HCMV TB40/E exposure. HCMV-luciferase activity in lung implants of GCV-treated LoM (orange boxes; $n=6$ ) and untreated control LoM (white boxes; days 4-21, $n=7$ and day 25,n=6) was compared with a two-tailed Mann-Whitney test. The median (horizontal line), upper and lower quartiles (box ends), and minimum to maximum values (whiskers) are shown. In a-k, $n=$ number of lung implants analyzed and horizontal lines represent mean \pm s.e.m. In $\mathbf{b}, \mathbf{d}, \mathbf{f}, \mathbf{h}, \mathbf{i}, \mathbf{I}$ and $\mathbf{m}$, scale bars shown for $\times 40(50 \mu \mathrm{m})$ and $\times 100(20 \mu \mathrm{m})$ images. In $\mathbf{b}, \mathbf{d}, \mathbf{h}$ and $\mathbf{~ m}$, the bottom left inset image represents the area indicated with a dashed box and nuclei are stained blue. $\mathrm{H}$, human; LNG, lung; p, photons. 
a

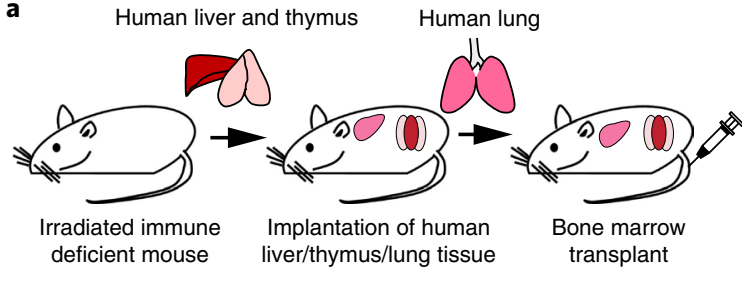

d
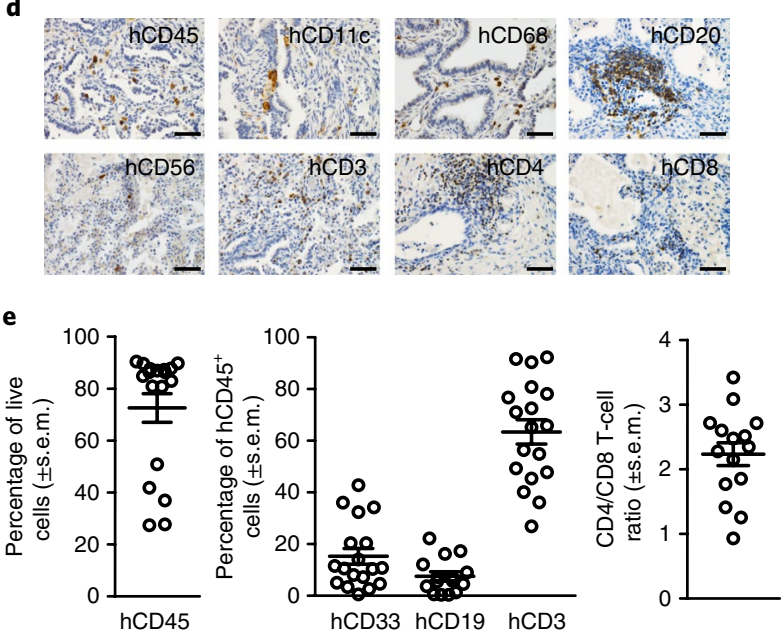

b

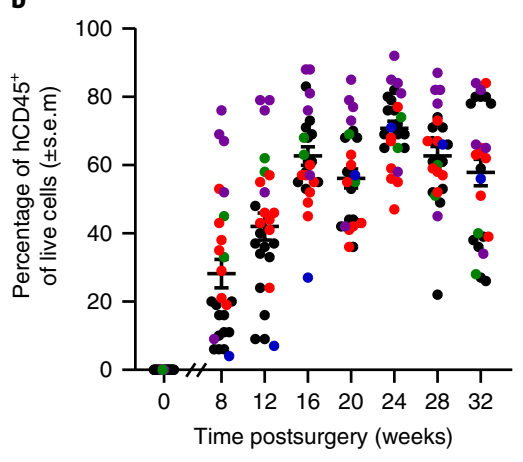

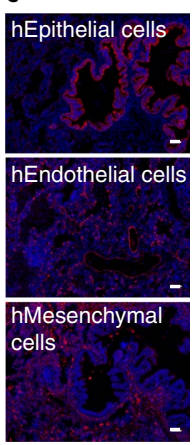

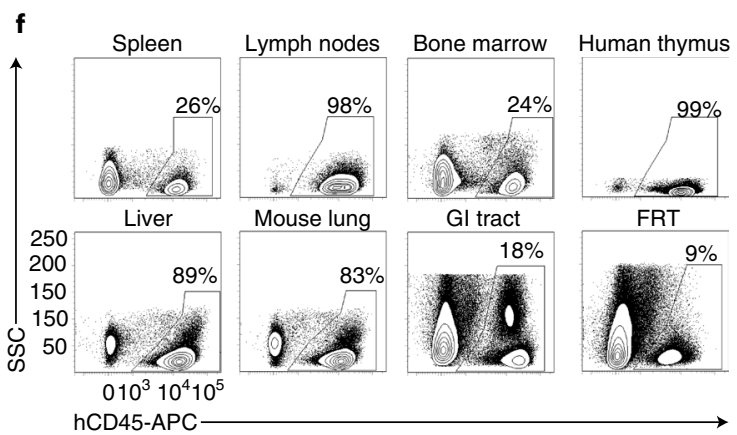

Fig. 3 | Systemic reconstitution of BLT-L humanized mice with human innate and adaptive immune cells. a, Construction of BLT- $L$ humanized mice. b, Human hematopoietic cells (hCD45+) in PB of BLT-L mice ( $n=26$ mice, 5 cohorts). Colors indicate BLT-L mouse cohorts. c, Immunofluorescence staining for human epithelial, endothelial and mesenchymal cells in a human lung implant of a BLT-L mouse ( $n=4$ mice analyzed; positive cells, red; nuclei, blue). Images shown are at $\times 10$ magnification (scale bars, $50 \mu \mathrm{m}$ ). d, Human hematopoietic (hCD45) cells including dendritic cells (hCD11c), macrophages (hCD68), B cells (hCD20), NK/NK T cells (hCD56) and T cells (hCD3, hCD4 and hCD8) in the human lung implant ( $n=3$ mice analyzed; positive cells, brown). Images shown are at $\times 40$ magnification (scale bars, $50 \mu \mathrm{m}$ ). e, Levels of hCD 45 cells including human myeloid cells (hCD33), B cells (hCD19) and T cells (hCD3) as well as the ratio of human CD4/CD8 T cells in the human lung implants (open circles) of BLT-L mice (hCD45, hCD33 and hCD3 analysis, $n=18$ implants; and hCD19 and hCD4/CD8 analysis, $n=15$ implants). f, Human CD45+ cells in tissues of BLT-L mice ( $n=4$ mice analyzed) by flow cytometry. GI, gastrointestinal. FRT, female reproductive tract. In $\mathbf{b}$ and $\mathbf{e}$, horizontal lines represent mean \pm s.e.m. SSC, side scatter.

in vivo has not been determined on a genome-wide scale due to the difficulty of obtaining acutely infected samples. To define the complement of HCMV genes expressed in human tissue in vivo, we injected cell-free HCMV TB40/E into the human lung implants of LoM. HCMV double-stranded complementary DNA ((ds)cDNA) was enriched with biotinylated probes spanning both strands of the entire HCMV genome and next generation sequencing used to measure viral gene expression. Using this approach, we were able to measure the complement of viral genes expressed in vivo in human tissue during lytic replication. Results revealed widespread HCMV gene expression spanning the viral genome, consistent with robust lytic replication (Supplementary Fig. 4). Expression of known lytic genes encoding IE proteins IE1 (UL123) and IE2 (UL122), early proteins (UL44 and UL38), and late proteins pp65 (UL83) and pp71 (UL82) were detected. By contrast, expression of UL138, a wellcharacterized latency gene, was not observed. These results serve as proof-of-principle of the utility of LoM to investigate key aspects of HCMV replication in human lung tissue in vivo.

The human innate and adaptive immune system of BLT-L mice. We generated an in vivo model with human lung implants and an autologous human immune system by constructing BLT mice with autologous human lung implants (BLT-L humanized mice). BLT-L mice were constructed by surgically implanting (1) autologous human thymus and liver tissue under the kidney capsule and (2) human lung tissue subcutaneously into the back of the same preconditioned (irradiated) immunodeficient mouse followed by bone marrow transplantation with autologous human hematopoietic stem cells (Fig. 3a). Over time, BLT-L mice developed human lung implants and robust levels of human hematopoietic cells $\left(\mathrm{hCD} 45^{+}\right)$ in peripheral blood $(\mathrm{PB})$ that were sustained for at least 8 months (last time analyzed) (Fig. 3b). The PB of BLT-L mice was reconstituted with human myeloid cells, B cells and T cells, including CD4 ${ }^{+}$ and $\mathrm{CD}^{+} \mathrm{T}$ cells (Supplementary Fig. 5).

In addition to human epithelial, endothelial and mesenchymal cells (Fig. 3c), human lung implants of BLT-L mice contained human innate and adaptive immune cells (Fig. 3d). Ex vivo stimulation of these cells with phorbol myristate acetate (PMA)/ionomycin or LPS demonstrated their broad capacity for human cytokine (pro-inflammatory and anti-inflammatory) and chemokine production (Supplementary Table 2). The human hematopoietic cells present in the human lung implants of BLT-L mice (hCD45 ${ }^{+}$, mean $72.5 \% \pm 5.5 \%$ s.e.m.; range $27.4-90.4 \%$ ) included human myeloid cells (hCD33 $3^{+}$mean $15.2 \% \pm 3.0 \%$ s.e.m.; range $0.5-42.8 \%$ ), $\mathrm{B}$ cells (hCD19+, mean $7.5 \% \pm 1.7 \%$ s.e.m.; range $0.4-22.2 \%$ ) and $\mathrm{T}$ cells $\left(\mathrm{hCD}^{+}\right.$, mean $63.4 \% \pm 4.6 \%$ s.e.m.; range $26.9-92.3 \%$ ) (Fig. 3e). No significant difference in human myeloid cell, B-cell or T-cell levels was observed between the human lung implants and mouse lung of BLT-L mice (Supplementary Fig. 6). CD4 ${ }^{+}$and $\mathrm{CD}^{+}$human $\mathrm{T}$ cells were present in the human lung implants of BLT-L mice. Human $\mathrm{CD}^{+}{ }^{+} \mathrm{T}$-cell levels were significantly lower $\left(P=6.472 \times 10^{-7}\right)$ and $\mathrm{CD}^{+}$T-cell levels were significantly higher $(P=0.0004)$ in the human lung implants of BLT-L mice compared with the mouse lung. The CD4/CD8 T-cell ratio (mean $2.2 \pm 0.17$ s.e.m.; range 0.93-3.42) in human lung implants (Fig. 3e) was similar to that observed in humans ${ }^{44}$. No difference in T-cell activation 
a

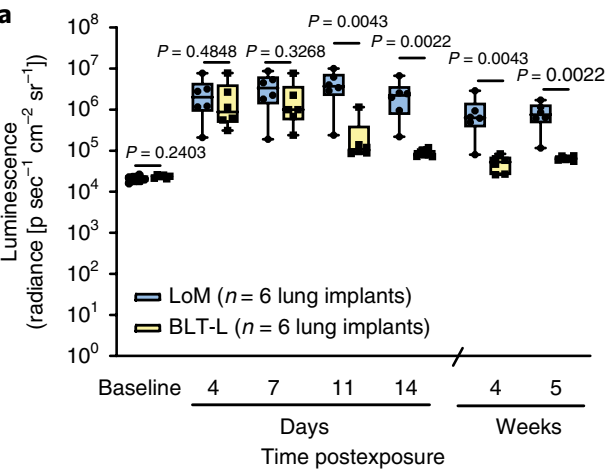

c 1xTB40IE - BLT-L12 (B) H LNG
Control pp65

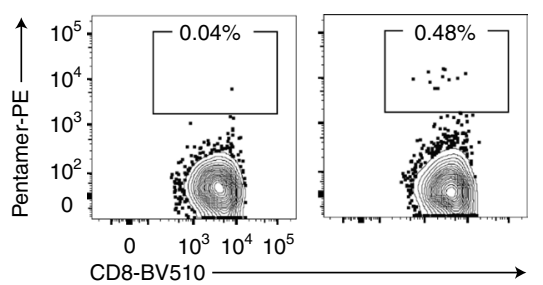

e

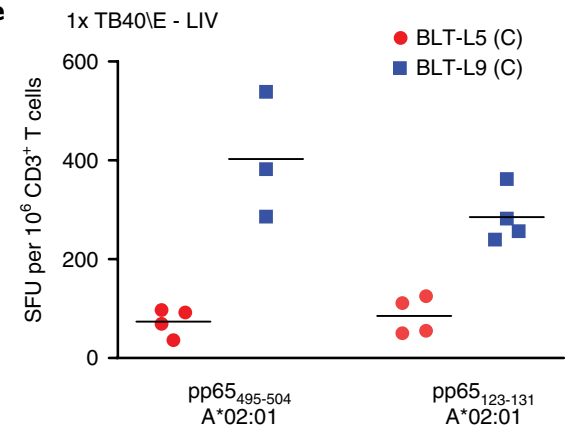

g

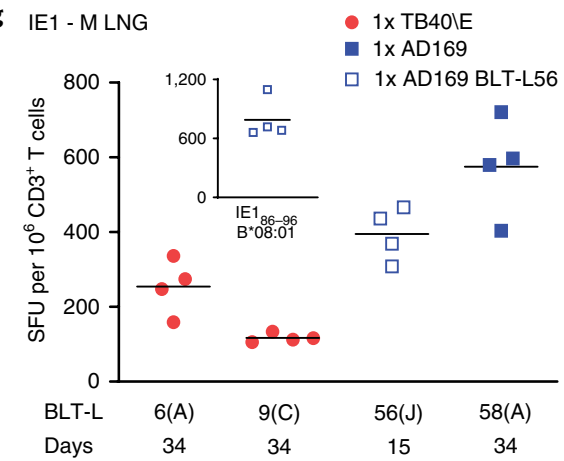

b

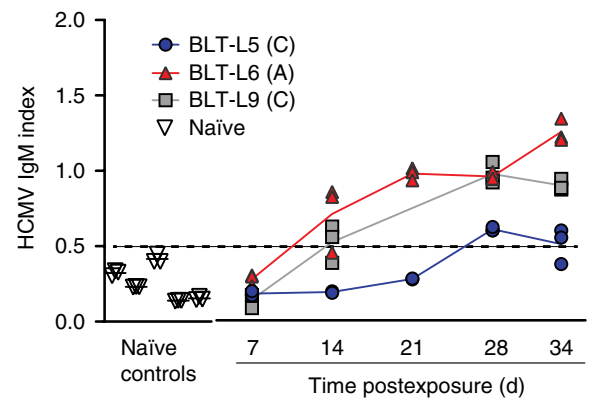

d 1xTB40\E - BLT-L2/-L3/-L4 (B) H LNG

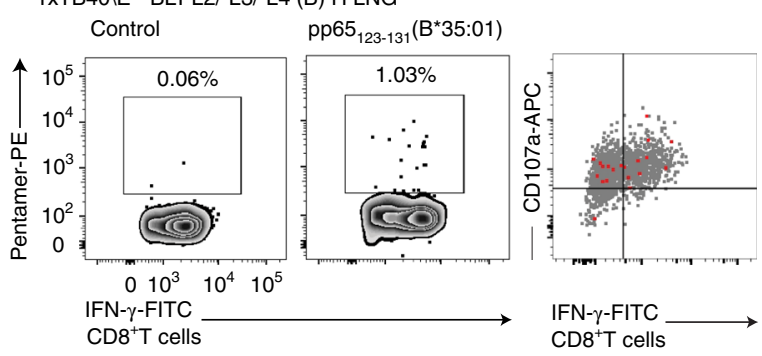

f IE1 - LIV

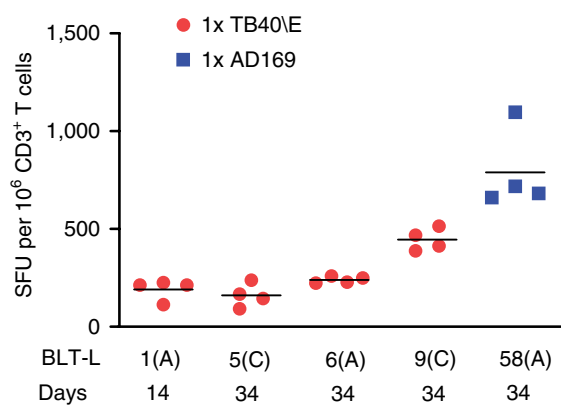

h 1XTB40।E

BLT-L8 (A) LIV $125 d$

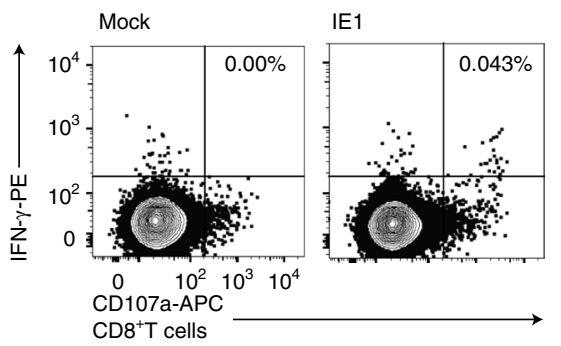

Fig. 4 | HCMV infection induces robust, sustained humoral and T-cell responses that control virus replication in BLT-L mice. a, HCMV TB40/E-luciferase activity in lung implants of LoM (blue boxes; $n=6$ implants) and BLT-L mice (yellow boxes; $n=6$ implants). Baseline, luminescence measured pre-exposure. The median (horizontal line), upper and lower quartiles (box ends), and minimum to maximum values (whiskers) are shown. Two-tailed Mann-Whitney test. b, HCMV-specific IgM in the plasma of HCMV-exposed BLT-L mice (TB40/E: BLT-L5 and BLT-L6, ADrUL131: BLT-L 9) and five naïve control BLT-L mice. Mean values (horizontal lines) and technical replicates are shown for each mouse. Dashed line, threshold for seropositivity defined from naïve mice. c, HCMV-specific CD8 ${ }^{+}$T cells detected by pentamer-reactivity in the lung implant (H LNG) of one BLT-L mouse $12 \mathrm{~d}$ postexposure. d, Pentamerreactive $\mathrm{HCMV}$-specific $\mathrm{CD} 8^{+} \mathrm{T}$ cells in the lung implant $21 \mathrm{~d}$ postexposure (left). Overlay of pentamer-reactive cells (red) on PMA/ionomycin-stimulated $\mathrm{CD}^{+} \mathrm{T}$ cells (gray) from one BLT-L mouse is shown (right). e, IFN- $\gamma$ ELISpot reactivity to commonly targeted CD8 ${ }^{+}$T-cell epitopes in human infection. Mean values (horizontal lines) and technical replicates are shown for two BLT-L mice. $\mathbf{f}, \mathbf{g}$, IFN- $\gamma$ ELISpot reactivity to the HCMV IE1 protein. Mean values (horizontal lines) and technical replicates are shown for six BLT-L mice. e- $\mathbf{g}$, ELISpot data are background subtracted. Criteria for positivity: $\geq 2 \times$ mean of replicate negative control wells and $>50$ SFU per million CD3 ${ }^{+} \mathrm{T}$ cells. $\mathbf{h}$, IE1-specific IFN- $\gamma^{+}$CD107a+ CD $8^{+}$T cells detected $125 \mathrm{~d}$ post-HCMV exposure in one BLT-L mouse. e-h, Cells were isolated from the liver (LIV) (e, $\mathbf{f}$ and $\mathbf{h}$ ) or mouse lung (M LNG) (g). b-h, BLT-L cohorts are indicated in parentheses. c-h, BLT-L mice were exposed to HCMV strain TB40/E or AD169 as indicated. Full details of immune reactivity for each BLT-L mouse are indicated in Supplementary Tables 4 and 5. p, photons. 
was observed (Supplementary Fig. 6). Memory $\left(\mathrm{CD} 45 \mathrm{RO}^{+}\right) \mathrm{CD}^{+}$ and $\mathrm{CD}^{+} \mathrm{T}$ cells were present in the human lung implants of BLT-L mice, the majority of which expressed an effector memory phenotype (CCR7-negative) (CD4 ${ }^{+} \mathrm{T}$ cells, mean $87.2 \% \pm 1.97 \%$ s.e.m.; range $81.8-90.8 \%$ and $\mathrm{CD}^{+} \mathrm{T}$ cells, mean $97.1 \% \pm 0.44 \%$ s.e.m.; range 96.1-97.9\%) (Supplementary Fig. 7a,b). We also identified the presence of $\mathrm{CD}^{+}$(mean $25.4 \% \pm 3.58 \%$ s.e.m.; range $18.5-$ $35.5 \%$ of memory $\mathrm{CD}^{+} \mathrm{T}$ cells) and $\mathrm{CD}^{+}$(mean $38.5 \% \pm 7.11 \%$ s.e.m.; range $21.0-51.8 \%$ of memory $\mathrm{CD}^{+} \mathrm{T}$ cells) tissue-resident memory $\mathrm{T}$ cells $\left(\mathrm{CD} 45 \mathrm{RO}^{+} \mathrm{CD} 69^{+}\right)$in the human lung implants of BLT-L mice, as observed in humans (Supplementary Fig. 7c,d) ${ }^{44}$. Similar to BLT mice, in addition to the human lung implant, human hematopoietic cells were systemically distributed throughout the animals including primary and secondary immune tissues (bone marrow, human thymic implant, spleen and lymph nodes), effector sites and mucosal tissues (lung, liver, gastrointestinal tract and female reproductive tract) of BLT-L mice (Fig. 3f). Innate and adaptive human immune cells were present in all tissues analyzed (Supplementary Fig. 7e).

Immune-mediated control of HCMV infection in BLT-L mice. LoM and BLT-L mice were inoculated with HCMV TB40/E expressing luciferase ${ }^{45}$. HCMV replication was detectable in the human lung implants of LoM and BLT-L mice at $4 \mathrm{~d}$ postinoculation (Fig. 4a). In LoM, robust HCMV replication was maintained up to 5 weeks postinoculation (last time point analyzed) (Fig. 4a). In contrast, in BLT-L mice HCMV replication began to decline by $11 \mathrm{~d}$ postinoculation (Fig. 4a). Luciferase activity in BLT-L mice was significantly lower compared with LoM (Fig. 4a). HCMV replication in BLT-L mice continued to decline over time (Fig. 4a). Specifically, luciferase activity in the human lung implants of BLT-L mice at week 4 (mean $5.10 \times 10^{4} \pm 2.25 \times 10^{4}$ s.e.m. radiance; range $2.68 \times 10^{4}-8.4 \times 10^{4}$ radiance) and week 5 (mean $6.46 \times 10^{4} \pm 8.08 \times 10^{3}$ s.e.m. radiance; range $5.5 \times 10^{4}-7.47 \times 10^{4}$ radiance) postinoculation approached baseline levels (mean $2.34 \times 10^{4}$ radiance) and was significantly lower compared with LoM (Fig. 4a). These results demonstrate that while the human lung implants of LoM and BLT-L mice support HCMV infection, in contrast to LoM, HCMV replication is efficiently controlled in BLT-L mice.

Levels of human cytokines and chemokines were analyzed in BLT-L mice pre- and post-HCMV TB40/E inoculation. At $4 \mathrm{~d}$ postinoculation, increased plasma levels of human GM-CSF, IFN- $\gamma$, IL-6, IL-8, MDC, IP-10, GRO and MCP-1 were detected (Supplementary Fig. 8). HCMV-specific human antibody and T-cell responses were examined in BLT-L mice exposed to the three different HCMV strains: TB40/E, AD169 and ADrUL131. AD169 is a well-characterized fibroblast-adapted laboratory strain that lacks the UL131 gene. ADrUL131 is an AD169 derivative in which UL131 is repaired ${ }^{46-48}$. $\mathrm{PB}$ plasma was collected longitudinally to measure HCMV-specific IgM levels. HCMV IgM levels in humans peak between 1 and 3 months after primary infection ${ }^{49}$. Consistent with human infection, HCMV IgM was detected as early as $14 \mathrm{~d}$ following TB40/E or ADrUL131 inoculation in different BLT-L cohorts (that is, mice generated from different human donor tissues) (Fig. 4b and Supplementary Tables 3 and 4).

To examine whether BLT-L mice induced $\mathrm{CD} 8^{+} \mathrm{T}$-cell responses to HCMV that are immunoprevalent in human infection, BLT-L donor tissue was HLA-typed (Supplementary Table 3) and reactivity to HCMV pentamers examined. HCMV infection induced classically HLA Ia-restricted HCMV pp65-specific $\mathrm{CD}^{+} \mathrm{T}$ cells in the human lung implant as early as $12 \mathrm{~d}$ following HCMV TB40/E inoculation (Fig. 4c,d and Supplementary Table 4). The functionality of these T cells was also examined by HCMV pentamer overlay of cells (mononuclear cells pooled from the liver of three mice, cohort B) stimulated with mitogen (Fig. 4d). All HCMV pentamerreactive $\mathrm{CD} 8^{+} \mathrm{T}$ cells (red events, Fig. 4 d right panel) were functional, producing the antiviral cytokine IFN- $\gamma$ or both IFN- $\gamma$ and the lytic granule marker CD107a.

Additional functional studies were performed using either ex vivo IFN- $\gamma$ enzyme-linked immunospot (ELISpot) assays or intracellular cytokine staining (ICS), in which irradiated autologous B-cell lines were used to present HCMV peptide epitopes or peptide pools (HCMV pp65 or IE1) to tissue cells (Supplementary Table 4). Here, we compared TB40/E and AD169 infection. Similar to TB40/E, AD169 induced T-cell responses to HLA-A and HLA-B pp65 peptide epitopes in BLT-L mice (Fig. 4e and Supplementary Table 5). Both strains also consistently induced T-cell responses to HCMV IE1 as early as $14 \mathrm{~d}$ postexposure (Fig. $4 \mathrm{f}, \mathrm{g}$ and Supplementary Table 5). IE1 is an immunoprevalent HCMV protein not found in virions but expressed after infection ${ }^{42}$. The detection of IE1-specific responses is consistent with the in vivo lytic replication of HCMV observed in Fig. 4a. HCMV-specific T-cell responses were detected in the human lung implant of BLT-L mice and systemically (liver and mouse lung) (Fig. $4 \mathrm{c}-\mathrm{h}$ ) and were maintained for up to $125 \mathrm{~d}$ (last time point analyzed) (Fig. 4h and Supplementary Table 4). Full details of T-cell reactivity are provided in Supplementary Table 4.

Our data demonstrating IE1-specific T-cell responses in BLT-L mice and a progressive decline in TB40/E-luciferase activity indicate that these mice were productively infected with HCMV, but, unlike LoM (Figs. $2 \mathrm{k}-\mathrm{n}$ and $4 \mathrm{a}$ and Supplementary Fig. 9), virus replication was controlled. HCMV DNA was readily detected in the human lung implants of all BLT-L mice analyzed $<14 \mathrm{~d}$ postexposure (Supplementary Table 6). However, consistent with the immunemediated virological control observed in BLT-L mice (Fig. 4a), only $55 \%$ of human lung implants analyzed between $14-34 \mathrm{~d}$ postexposure, and none of the human lung implants analyzed after $34 \mathrm{~d}$ postexposure, had detectable levels of viral DNA (Supplementary Table 6). HCMV DNA was rarely detected in other tissues analyzed (12 of 135) (Supplementary Table 6), suggesting that HCMV dissemination to peripheral tissues was limited and/or replication controlled.

Re-exposure boosts antibody and T-cell responses to HCMV. To mimic the ongoing antigenic exposure that occurs during chronic HCMV infection, we investigated the effect of repeated HCMV exposure on host immune responses. Mice were inoculated with 3-4 doses of HCMV TB40/E or AD169.

Over $90 \%$ (22 of 24) of mice had detectable HCMV-specific IgM following repeated (3-4 times) HCMV exposure, regardless of the infecting HCMV strain (Fig. 5a). HCMV-specific IgG was detected in $\sim 73 \%$ (16 of 22) of re-exposed BLT-L mice (Fig. 5b), demonstrating efficient class switching. Plasma samples collected from BLT-L mice repeatedly exposed to TB40/E and with detectable HCMV-specific IgM and IgG possessed neutralizing activity, reducing HCMV infection in vitro by up to $91 \%$ (Supplementary Fig. 10). The time from first HCMV exposure to antibody testing differed between singly or multiply exposed mice ( 1 dose: mean $48 \mathrm{~d}$ postexposure, range $12-125 \mathrm{~d}$; and 3-4 doses: mean $77 \mathrm{~d}$ postexposure, range $42-120 \mathrm{~d}$ ). We cannot therefore exclude that time, in addition to repeated antigen exposure, contributed to class switching. However, TB40/E failed to induce HCMV-specific IgG $125 \mathrm{~d}$ after a single exposure (Fig. 5b and Supplementary Table 4), despite the presence of a detectable HCMV-specific CD8 ${ }^{+}$T-cell response (Fig. 4h).

HCMV infection induces robust and sustained $\mathrm{CD}^{+}{ }^{+} \mathrm{T}$-cell responses $^{50}$. In BLT-L mice inoculated once with HCMV, we were unable to detect $\mathrm{HCMV}$-specific $\mathrm{CD}^{+}{ }^{+} \mathrm{T}$-cell responses by ICS (data not shown). However, following repeated HCMV exposure, IE1-specific CD4 ${ }^{+}$T-cell cytokine responses were detected in the human lung implant and liver of BLT-L mice, suggesting that repeated antigen exposure induced or augmented antigen-specific CD4 ${ }^{+}$T-cell responses (Fig. 5c). IE1-specific CD8 ${ }^{+}$ T-cell responses measured by ICS were detected more frequently in repeatedly HCMV-exposed mice than in singly exposed 
a

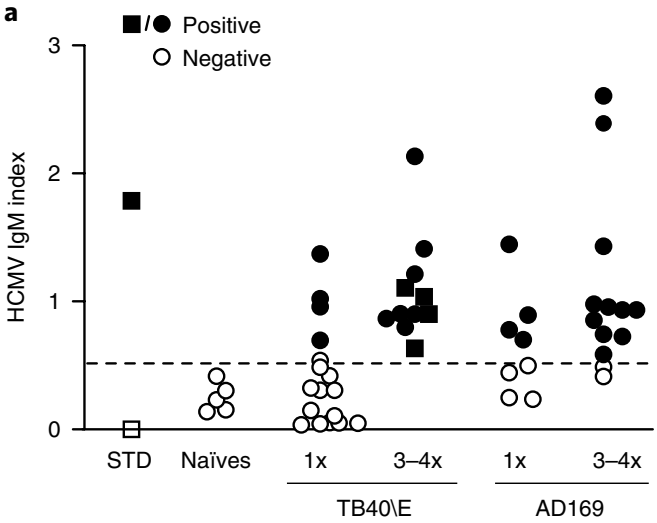

C $\quad 4 \times \mathrm{AD} 169-\mathrm{BLT}-\mathrm{L} 53(\mathrm{H})$

Mock IE1

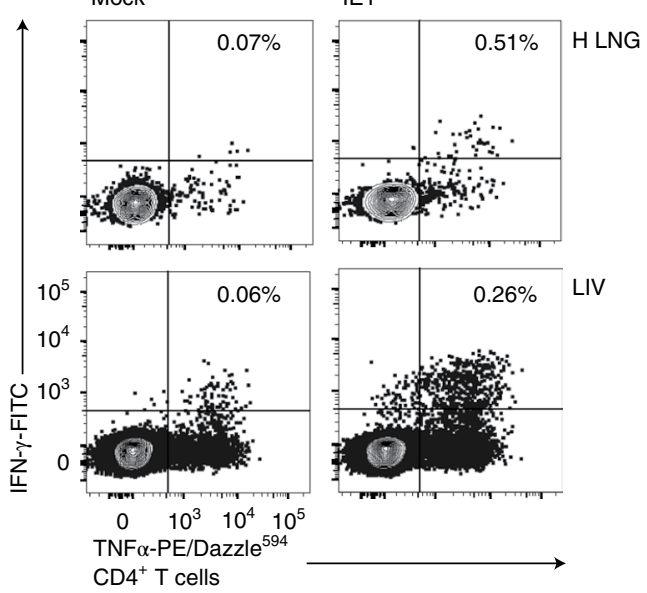

e

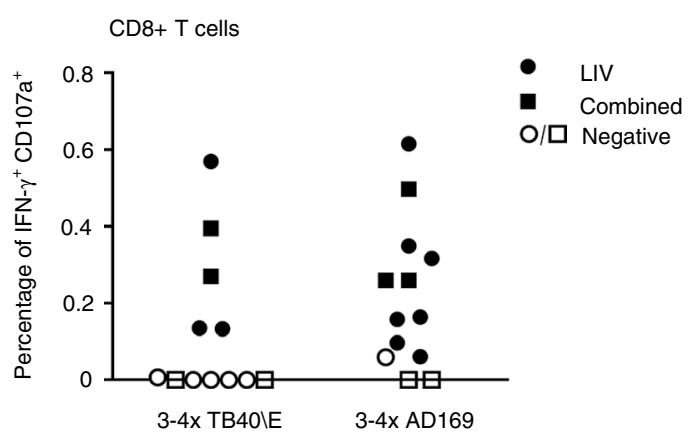

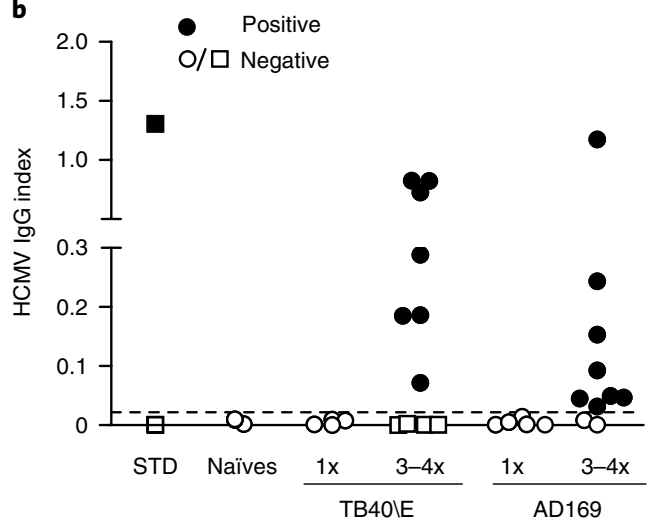

d Combined tissues - Donor $\mathrm{E}$ Mock

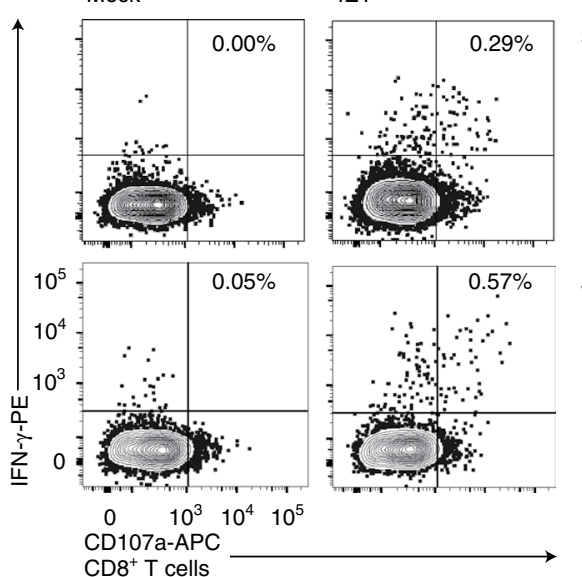

3x TB40\E

BLT-L32

f $\mathrm{H}$ LNG

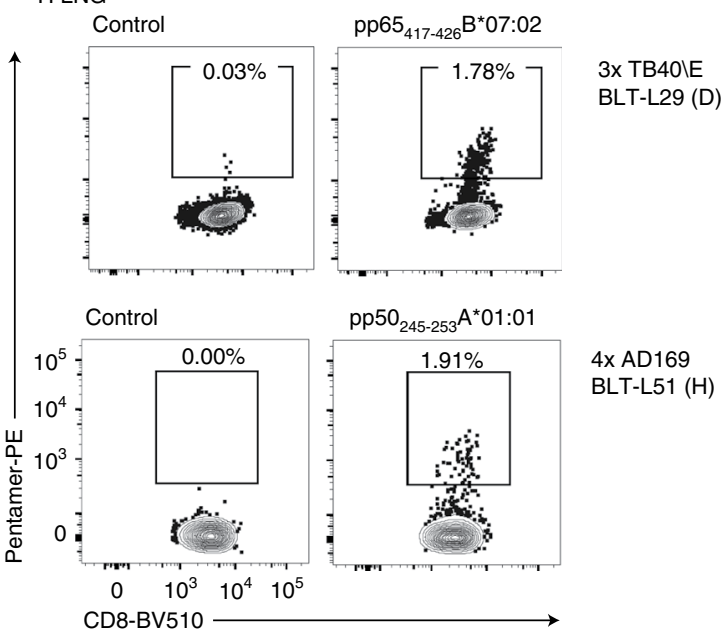

Fig. 5 | HCMV re-exposure further promotes antibody induction and class switching and boosts HCMV-specific T-cell responses in BLT-L mice. a,b, HCMV-specific IgM (a) and IgG (b) in naïve BLT-L mice $(n=5)$ and following single or 3-4 exposures to HCMV TB40/E (IgM $n=15$ single and 11 re-exposed mice, $\lg n n=4$ single and 11 re-exposed mice) or AD169 (IgM $n=8$ single and 13 re-exposed mice, IgG $n=4$ single and 11 re-exposed mice). Negative (open diamonds) and positive (filled diamonds) standards (STD). Shown is the mean of three technical replicates per mouse. Dashed line, threshold for seropositivity defined from naïve controls. c, HCMV re-exposure induced IE1-specific TNF- $\alpha /$ IFN- $\gamma$ double positive CD4+ ${ }^{+}$cells at the site of inoculation, the human lung implant and systemically in the liver. Contour plots exampling HCMV-IE1-specific CD8 ${ }^{+} \mathrm{T}$-cell IFN- $\gamma$ production and CD107a degranulation in a BLT-L mouse. $\mathbf{d}, C D 8^{+}$T cells were isolated from combined tissues of TB40/E (top panels representative of measurements in 4 independent BLT-L mice) or AD169 (bottom panels representative of measurements in 11 independent BLT-L mice) exposed mice, stimulated and then assessed using ICS. e, Summary graph showing background subtracted IE1-specific CD8 ${ }^{+}$T-cell responses (IFN- $\gamma$ production) in mice receiving repeated inoculations of TB40/E or AD169. Filled symbols show positive responses and open symbols indicate negative responses. TB40/E open squares and circles represent mice in cohorts D and F, respectively; AD169 open squares and circles represent mice in cohorts D and E, respectively. f, Repeated TB40/E (top panels representative of measurements in four independent BLT-L mice) and AD169 (bottom panels representative of measurements in four independent BLT-L mice) exposure induced high frequencies of HCMV-specific CD $8^{+} T$ cells as determined by pentamer reactivity. Full details of immune reactivity for each multiple exposed BLT-L mouse are indicated in Supplementary Tables 7 and 8. 
BLT-L mice (Fischer's exact, two-tailed $P=0.039$ ) (Fig. 5d,e and Supplementary Tables 4, 7 and 8). Repeated HCMV exposure also induced stronger $\mathrm{HCMV}$-specific $\mathrm{CD}^{+} \mathrm{T}$-cell responses across tissues (Figs. $4 \mathrm{~h}$ and $5 \mathrm{~d}-\mathrm{f}$ ), producing $\mathrm{T}$-cell responses consistent with those reported in human HCMV infection ${ }^{51-54}$. Increases in pentamer reactivity were also observed. Classically restricted $\mathrm{HCMV}$-specific $\mathrm{CD} 8^{+} \mathrm{T}$ cells in repeat exposure BLT-L mice approached $2 \%$ of all $\mathrm{CD}^{+}{ }^{+} \mathrm{T}$ cells (Fig. 5 f), between 4 - and 15 -fold greater than pentamer frequencies observed following a single exposure (Fig. 4c,d and data not shown). Full details of immune reactivity following repeated HCMV inoculation are provided in Supplementary Tables 7 and 8.

Although BLT-L mice were exposed to multiple doses of TB40/E or AD169, HCMV DNA was only detected in the human lung implants of 9 of 18 mice analyzed (2 TB40/E- and 7 AD169-exposed BLT-L mice) (Supplementary Tables 9 and 10). HCMV DNA was rarely detected in tissues other than the human lung implants (3 of 108 tissues analyzed) and was not detected in PB (Supplementary Tables 9 and 10), suggesting strong immune control of HCMV replication in vivo.

\section{Discussion}

To extend the breadth of human pathogens that can be studied using humanized mice, we validated two models, LoM and BLT-L mice, which provide human lung tissue as an in vivo target for human pathogens either without (LoM) or with (BLT-L mice) an autologous systemic human immune system. The engraftment levels of human immune cell types in BLT-L mice are similar to previously reported BLT mice ${ }^{55-57}$. The subcutaneously implanted human lung tissue expands and develops into lung implants containing human epithelial, endothelial and mesenchymal cells and a vasculature of human origin. Located just underneath the skin, the lung implants can be readily accessed and imaged.

Using LoM, we demonstrated that the human lung implants are susceptible to five diverse emerging and clinically relevant human pathogens (MERS-CoV, ZIKV, mycobacteria, RSV and $\mathrm{HCMV}$ ) without further engineering of the pathogens or the host. However, it is possible that a respiring lung will have different host gene expression profiles, which could alter the replication conditions of some pathogens. We next demonstrated that pre-exposure prophylaxis with GCV can effectively control HCMV replication in LoM and performed an in vivo transcriptome analysis of lytic HCMV infection. In the future, transcriptome analyses of the pathogen and host may identify new drug targets and host factors that modulate infection.

HCMV infection in BLT-L mice produced acute virus kinetics that reflected lytic replication, consistent with those reported in humans. With the onset of adaptive humoral and T-cell responses, HCMV replication in BLT-L mice declined to background levels. Whereas HCMV DNA was detected in all exposed LoM, HCMV DNA was only detected in BLT-L mice during the first 2 weeks postinfection, consistent with the strong virological immune control observed. $\mathrm{CD}^{+}{ }^{+} \mathrm{T}$-cell responses were detectable in the lung implant as early as $12 \mathrm{~d}$ postinoculation to multiple epitopes including the IE1 and pp65 proteins, which are targeted in 50\% of human patients ${ }^{58}$. HCMV-specific $\mathrm{T}$ cells were detected systemically in the liver and mouse lung. HCMV-specific $\mathrm{CD}^{+}$ $\mathrm{T}$-cell responses were detected up to $125 \mathrm{~d}$ following inoculation. The induction of a systemic antigen-specific immune response in BLT-L mice, combined with our data demonstrating the production of human cytokines/chemokines following ex vivo mitogen stimulation of human immune cells isolated from the lung implants, demonstrates the functionality of the human immune cells that repopulate the lung implants.

Mimicking the ongoing antigenic exposure that occurs during chronic HCMV infection, multiple exposures to HCMV resulted in a more robust HCMV-specific antibody and T-cell response in BLT-L mice. We readily detected HCMV-specific IgG in BLT-L mice re-exposed to TB40/E or AD169, suggesting that repeat antigen stimulation facilitates human IgG class switching. Multiple HCMV exposures also induced a robust $\mathrm{HCMV}$-specific T-cell response. Natural HCMV infection in humans elicits a life-long $\mathrm{CD} 4^{+}$and $\mathrm{CD}^{+} \mathrm{T}$-cell response and very high reactivity $(80-100 \%)$ to IE1 and pp65 proteins ${ }^{58,59}$. We readily observed IE1-specific CD4 $4^{+} \mathrm{T}$ cells in multiple tissues of BLT-L mice repeatedly exposed to HCMV. The magnitude of the HCMV-specific $\mathrm{CD}^{+} \mathrm{T}$-cell response was also increased in BLT-L mice exposed to multiple doses of HCMV and reached levels comparable to humans ${ }^{52-54,60,61}$. The fact that repeated exposure can be used to broaden the immunoprevalence of T-cell responses in BLT-L mice suggests that the model might be useful in vaccine testing.

We did not observe an $\mathrm{HCMV}$-specific $\mathrm{CD} 8^{+} \mathrm{T}$-cell response or HCMV-specific IgG in cohort F of BLT-L mice, despite multiple exposures to TB40/E. This cohort (F) was homozygous across all class Ia and II alleles (Supplementary Table 3). HCMV induced low levels of IgM but no class switching was observed (Fig. 5a,b, square symbols). Despite a 111-120 d follow-up (postfirst HCMV exposure), no IE1-specific T-cell IFN- $\gamma^{+} / \mathrm{CD} 107 \mathrm{a}^{+}$ responses were detected (Fig. 5e and Supplementary Table 7). $\mathrm{T}$ cells and myeloid dendritic cells (mDCs) in this cohort were functional; specifically, mitogenic stimulation of $\mathrm{T}$ cells induced potent cytokine production and degranulation, and autologous mDCs induced a mixed-lymphocyte reaction when cocultured with allogeneic peripheral blood mononuclear cells (data not shown). These results suggest that a limited repertoire of HLApresented viral peptides impedes the generation of antigen-specific adaptive immune response in vivo.

BLT-L mice generate antigen-specific humoral and cell-mediated immune responses that control pathogen replication in vivo. These results validate BLT-L mice as an in vivo platform to study the replication, pathogenesis and immunogenicity of human pathogens in the context of a functional systemic human immune system. In this regard, BLT-L mice would support the type of direct, systematic and sophisticated in vivo experimentation that is characteristic of rodent models but cannot be performed in humans. Our results also support BLT-L mice as a model for the in vivo evaluation of human immune therapies, including vaccines, especially for diseases with a strict species tropism.

In summary, we have developed two humanized mouse models that support infection and replication of important human viral and bacterial pathogens. LoM and BLT-L mice could be used to study other human pathogens that target the lung (for example, enterovirus D68, adenovirus type 7, influenza virus, rhinovirus and metapneumovirus), accelerating the in vivo testing of preventative and therapeutic approaches for these agents. Our analysis of implant vascularization using 3D ultrasound acoustic angiography, a noninvasive technique to visualize microvasculature, also suggests that this technology can be used for monitoring angiogenesis and vascularization in other systems. Our results also suggest that developing additional in vivo humanized mouse models for human pathogens with tropism for other tissues might be possible and might enhance the precision of humanized mouse models for biomedical research.

\section{Online content}

Any methods, additional references, Nature Research reporting summaries, source data, statements of code and data availability and associated accession codes are available at https://doi.org/10.1038/ s41587-019-0225-9.

Received: 4 December 2018; Accepted: 12 July 2019; Published online: 26 August 2019 


\section{References}

1. Cockrell, A. S. et al. A mouse model for MERS coronavirus-induced acute respiratory distress syndrome. Nat. Microbiol. 2, 16226 (2016).

2. Morrison, T. E. \& Diamond, M. S. Animal models of Zika virus infection, pathogenesis, and immunity. J. Virol. 91, e00009-17 (2017).

3. Safronetz, D., Geisbert, T. W. \& Feldmann, H. Animal models for highly pathogenic emerging viruses. Curr. Opin. Virol. 3, 205-209 (2013).

4. Schmitt, K. et al. Zika viral infection and neutralizing human antibody response in a BLT humanized mouse model. Virology 515, 235-242 (2018).

5. Crawford, L. B., Streblow, D. N., Hakki, M., Nelson, J. A. \& Caposio, P. Humanized mouse models of human cytomegalovirus infection. Curr. Opin Virol. 13, 86-92 (2015)

6. Taylor, G. Animal models of respiratory syncytial virus infection. Vaccine 35, 469-480 (2017).

7. Gupta, U. D. \& Katoch, V. M. Animal models of tuberculosis. Tuberculosis (Edinb.) 85, 277-293 (2005).

8. Fonseca, K. L., Rodrigues, P. N. S., Olsson, I. A. S. \& Saraiva, M. Experimental study of tuberculosis: from animal models to complex cell systems and organoids. PLoS Pathog. 13, e1006421 (2017).

9. Pickles, R. J. \& DeVincenzo, J. P. Respiratory syncytial virus (RSV) and its propensity for causing bronchiolitis. J. Pathol. 235, 266-276 (2015).

10. Perlman, R. L. Mouse models of human disease: an evolutionary perspective. Evol. Med. Public Health 2016, 170-176 (2016).

11. Shultz, L. D., Brehm, M. A., Garcia-Martinez, J. V. \& Greiner, D. L. Humanized mice for immune system investigation: progress, promise and challenges. Nat. Rev. Immunol. 12, 786-798 (2012).

12. Garcia, J. V. Humanized mice for HIV and AIDS research. Curr. Opin. Virol. 19, 56-64 (2016)

13. Wahl, A. et al. A cluster of virus-encoded microRNAs accelerates acute systemic Epstein-Barr virus infection but does not significantly enhance virus-induced oncogenesis in vivo. J. Virol. 87, 5437-5446 (2013).

14. Melkus, M. W. et al. Humanized mice mount specific adaptive and innate immune responses to EBV and TSST-1. Nat. Med. 12, 1316-1322 (2006).

15. Islas-Ohlmayer, $M$. et al. Experimental infection of NOD/SCID mice reconstituted with human $\mathrm{CD} 34^{+}$cells with Epstein-Barr virus. J. Virol. 78, 13891-13900 (2004)

16. Bente, D. A., Melkus, M. W., Garcia, J. V. \& Rico-Hesse, R. Dengue fever in humanized NOD/SCID mice. J. Virol. 79, 13797-13799 (2005).

17. Smith, M. S. et al. Granulocyte-colony stimulating factor reactivates human cytomegalovirus in a latently infected humanized mouse model. Cell Host Microbe 8, 284-291 (2010).

18. Crawford, L. B. et al. Human cytomegalovirus induces cellular and humoral virus-specific immune responses in humanized BLT mice. Sci. Rep. 7, 937 (2017).

19. Wang, L. X. et al. Humanized-BLT mouse model of Kaposi's sarcomaassociated herpesvirus infection. Proc. Natl Acad. Sci. USA 111, 3146-3151 (2014).

20. Cockrell, A. S. et al. Mouse dipeptidyl peptidase 4 is not a functional receptor for Middle East respiratory syndrome coronavirus infection. J. Virol. 88, 5195-5199 (2014).

21. Coleman, C. M., Matthews, K. L., Goicochea, L. \& Frieman, M. B. Wild-type and innate immune-deficient mice are not susceptible to the Middle East respiratory syndrome coronavirus. J. Gen. Virol. 95, 408-412 (2014).

22. Martinez-Torres, F., Nochi, T., Wahl, A., Garcia, J. V. \& Denton, P. W. Hypogammaglobulinemia in BLT humanized mice-an animal model of primary antibody deficiency. PloS ONE 9, e108663 (2014).

23. Nochi, T., Denton, P. W., Wahl, A. \& Garcia, J. V. Cryptopatches are essential for the development of human GALT. Cell Rep. 3, 1874-1884 (2013).

24. Dudek, T. E. et al. Rapid evolution of HIV-1 to functional CD8(+) T cell responses in humanized BLT mice. Sci. Transl. Med. 4, 143 ra198 (2012).

25. Brainard, D. M. et al. Induction of robust cellular and humoral virus-specific adaptive immune responses in human immunodeficiency virus-infected humanized BLT mice. J. Virol. 83, 7305-7321 (2009).

26. Zhou, J., Chu, H., Chan, J. F. \& Yuen, K. Y. Middle East respiratory syndrome coronavirus infection: virus-host cell interactions and implications on pathogenesis. Virol. J. 12, 218 (2015)

27. Frumence, E. et al. The South Pacific epidemic strain of Zika virus replicates efficiently in human epithelial A549 cells leading to IFN- $\beta$ production and apoptosis induction. Virology 493, 217-226 (2016).

28. Liu, S., DeLalio, L. J., Isakson, B. E. \& Wang, T. T. AXL-mediated productive infection of human endothelial cells by Zika virus. Circ. Res. 119, 1183-1189 (2016).

29. Hamel, R. et al. Biology of Zika virus infection in human skin cells. J. Virol. 89, 8880-8896 (2015).

30. Franks, T. J. et al. Resident cellular components of the human lung: current knowledge and goals for research on cell phenotyping and function. Proc. Am. Thorac. Soc. 5, 763-766 (2008).

31. Sousa, A. Q. et al. Postmortem findings for 7 neonates with congenital Zika virus infection. Emerg. Infect. Dis. 23, 1164-1167 (2017).
32. Cunha, B. A. Cytomegalovirus pneumonia: community-acquired pneumonia in immunocompetent hosts. Infect. Dis. Clin. North Am. 24, 147-158 (2010)

33. Gordon, C. L. et al. Tissue reservoirs of antiviral T cell immunity in persistent human CMV infection. J. Exp. Med. 214, 651-667 (2017).

34. Lyon, S. M. \& Rossman, M. D. Pulmonary tuberculosis. Microbiol. Spectr. 5, $1-13$ (2017)

35. Gessner, R. et al. High-resolution, high-contrast ultrasound imaging using a prototype dual-frequency transducer: in vitro and in vivo studies. IEEE Trans. Ultrason. Ferroelectr. Freq. Control 57, 1772-1781 (2010).

36. Gessner, R. C., Frederick, C. B., Foster, F. S. \& Dayton, P. A. Acoustic angiography: a new imaging modality for assessing microvasculature architecture. International J. Biomed. Imaging 2013, 936593 (2013).

37. Davis, L. S. et al. Inflammation, immune reactivity, and angiogenesis in a severe combined immunodeficiency model of rheumatoid arthritis. Am. J. Pathol. 160, 357-367 (2002).

38. Huang, S. Y., Tien, H. F., Su, F. H. \& Hsu, S. M. Nonirradiated NOD/ SCID-human chimeric animal model for primary human multiple myeloma: a potential in vivo culture system. Am. J. Pathol. 164, 747-756 (2004).

39. Hou, W. et al. Determination of the cell permissiveness spectrum, mode of RNA replication, and RNA-protein interaction of Zika virus. BMC Infect. Dis. 17, 239 (2017).

40. Liesman, R. M. et al. RSV-encoded NS2 promotes epithelial cell shedding and distal airway obstruction. J. Clin. Invest. 124, 2219-2233 (2014)

41. Aherne, W., Bird, T., Court, S. D., Gardner, P. S. \& McQuillin, J. Pathological changes in virus infections of the lower respiratory tract in children. J. Clin. Pathol. 23, 7-18 (1970).

42. Arend, K. C., Ziehr, B., Vincent, H. A. \& Moorman, N. J. Multiple transcripts encode full-length human cytomegalovirus IE1 and IE2 proteins during lytic infection. J. Virol. 90, 8855-8865 (2016).

43. Azevedo, L. S. et al. Cytomegalovirus infection in transplant recipients. Clinics (Sao Paulo) 70, 515-523 (2015).

44. Sathaliyawala, T. et al. Distribution and compartmentalization of human circulating and tissue-resident memory T cell subsets. Immunity $\mathbf{3 8}$, 187-197 (2013).

45. Pitt, E. A. et al. The D-form of a novel heparan binding peptide decreases cytomegalovirus infection in vivo and in vitro. Antiviral Res. 135 15-23 (2016).

46. Sinzger, C. et al. Cloning and sequencing of a highly productive, endotheliotropic virus strain derived from human cytomegalovirus TB40/E. J. Gen. Virol. 89, 359-368 (2008).

47. Ostermann, E., Spohn, M., Indenbirken, D. \& Brune, W. Complete genome sequence of a human cytomegalovirus strain AD169 bacterial artificial chromosome clone. Genome Announc. 4, 1-2 (2016).

48. Wang, D. \& Shenk, T. Human cytomegalovirus UL131 open reading frame is required for epithelial cell tropism. J. Virol. 79, 10330-10338 (2005).

49. Munro, S. C. et al. Diagnosis of and screening for cytomegalovirus infection in pregnant women. J. Clin. Microbiol. 43, 4713-4718 (2005).

50. Gamadia, L. E., Rentenaar, R. J., van Lier, R. A. \& ten Berge, I. J. Properties of CD4(+) T cells in human cytomegalovirus infection. Hum. Immunol. 65, 486-492 (2004).

51. Vaz-Santiago, J. et al. Ex vivo stimulation and expansion of both CD4(+) and CD8(+) T cells from peripheral blood mononuclear cells of human cytomegalovirus-seropositive blood donors by using a soluble recombinant chimeric protein, IE1-pp65. J. Virol. 75, 7840-7847 (2001).

52. Sinclair, E. et al. CMV antigen-specific $\mathrm{CD} 4^{+}$and $\mathrm{CD}^{+} \mathrm{T}$ cell IFN $\gamma$ expression and proliferation responses in healthy CMV-seropositive individuals. Viral Immunol. 17, 445-454 (2004).

53. Gillespie, G. M. et al. Functional heterogeneity and high frequencies of cytomegalovirus-specific CD8(+) T lymphocytes in healthy seropositive donors. J. Virol. 74, 8140-8150 (2000)

54. Nastke, M. D. et al. Major contribution of codominant CD8 and CD4 T cell epitopes to the human cytomegalovirus-specific T cell repertoire. Cell. Mol. Life Sci. 62, 77-86 (2005).

55. Kessing, C. F. et al. In vivo suppression of HIV rebound by didehydrocortistatin a, a "block-and-lock" strategy for HIV-1 treatment. Cell Rep. 21, 600-611 (2017)

56. Kovarova, M. et al. A long-acting formulation of the integrase inhibitor raltegravir protects humanized BLT mice from repeated high-dose vaginal HIV challenges. J. Antimicrob. Chemother. 71, 1586-1596 (2016).

57. Tsai, P. et al. CD19xCD3 DART protein mediates human B-cell depletion in vivo in humanized BLT mice. Mol. Ther. Oncolytics 3, 15024 (2016).

58. Lilleri, D., Zelini, P., Fornara, C., Comolli, G. \& Gerna, G. Inconsistent responses of cytomegalovirus-specific T cells to pp65 and IE-1 versus infected dendritic cells in organ transplant recipients. Am. J. Transplant. 7, 1997-2005 (2007)

59. Jackson, S. E., Mason, G. M., Okecha, G., Sissons, J. G. \& Wills, M. R. Diverse specificities, phenotypes, and antiviral activities of cytomegalovirusspecific CD8+ T cells. J. Virol. 88, 10894-10908 (2014). 
60. Braendstrup, P. et al. Identification and HLA-tetramer-validation of human $\mathrm{CD}^{+}$and $\mathrm{CD}^{+} \mathrm{T}$ cell responses against HCMV proteins IE1 and IE2. PloS ONE 9, e94892 (2014).

61. Khan, N., Cobbold, M., Keenan, R. \& Moss, P. A. Comparative analysis of $\mathrm{CD}^{+} \mathrm{T}$ cell responses against human cytomegalovirus proteins pp65 and immediate early 1 shows similarities in precursor frequency, oligoclonality, and phenotype. J. Infect. Dis. 185, 1025-1034 (2002).

\section{Acknowledgements}

This work was supported by NIH grants no. AI103311 (N.J.M.), no. AI123811 (N.J.M.), no. AI1 10700 (R.S.B.), no. AI100625 (R.S.B.), no. P30 AI027763 (N.G.), no. AI113736 (R.J.P.), no. T32 HL069768 (I.G.N.), no. AI123010 (A.W.), no. AI111899 (J.V.G.), no AI140799 (J.V.G.), no. MH108179 (J.V.G.), no. CA189479 (P.A.D.) and no. CA170665 (P.A.D) and the North Carolina University Cancer Research Fund (N.J.M.). This work was also supported by the UNC Center for AIDS Research (CFAR) (grant no. P30 AI050410). We thank K. Arend for the generation of HCMV virus stocks used in these experiments. We thank P. Collins and M. Peeples for recombinant RSV expressing GFP and C. O'Connor for recombinant HCMV TB40/E expressing luciferase. We thank G. Clutton for input on the analysis of antigen-specific T-cell responses. The authors thank members of the Garcia laboratory for technical assistance. We thank technicians at the UNC Animal Histopathology Core, The Marsico Lung Institute Tissue and Procurement Core, and the Department of Comparative Medicine. We also thank J. Schmitz and technicians at the UNC Clinical Microbiology/Immunology Laboratories. We thank J. Nelson and technicians at the UNC CFAR Virology Core Laboratory and K. Mollan at the UNC CFAR Biostatistics Core. The authors thank M.T. Heise, L.J. Picker and J.P. Ting for manuscript advice and helpful discussions.

\section{Author contributions}

A.W. inoculated mice with HCMV; collected and processed PB and tissues from HCMV-exposed mice; performed experiments with $\mathrm{PB}$ and tissue cells and analyzed the data; performed the flow cytometric and IHC analysis of naïve LoM and BLT-L mice; performed the human cytokine/chemokine analysis; inoculated mice with BCG and collected tissues from BCG-exposed mice; conceived and designed experiments; contributed to data interpretation, data presentation and manuscript writing; and conceived, designed and coordinated the study, the preparation of the manuscript and its revision. C.D. inoculated mice with HCMV; performed the GCV experiment, the in vivo imaging of mice and neutralization assay; collected and processed $\mathrm{PB}$ and tissues from HCMV-exposed mice; performed experiments with PB and tissue cells and analyzed the data; performed the human cytokine/chemokine analysis; inoculated mice with RSV; and collected and processed tissues and measured RSV-GFP expression by flow cytometry. M.A.F. performed experiments with PB and tissue cells and analyzed the data; standardized, designed, performed and analyzed immunological assays; and contributed to data interpretation, data presentation and manuscript writing. E.M.L. performed experiments with $\mathrm{PB}$ and tissue cells and analyzed the data and performed the HCMV real-time PCR analyses. Y.X. performed experiments with PB and tissue cells and analyzed the data and standardized, designed, performed and analyzed immunological assays. A.S.C. produced stocks of MERS-CoV; inoculated mice with MERS-CoV and collected tissues from MERS-CoV infected animals; conceived and designed experiments; and contributed to data interpretation, data presentation and manuscript writing. R.A.C. performed dual immunofluorescence staining of infected LoM. C.E.J. performed immunofluorescence staining of animals, collected tissues from BCG-exposed mice and performed the acid-fast staining. N.J.S. produced stocks of ZIKV, inoculated mice with ZIKV, and collected and processed tissue from ZIKVinfected mice. L.M.R. processed and cultured tissue homogenate to determine the number of the BCG c.f.u. and the analyzed data. I.G.N. performed the ultrasound and acoustic angiography imaging and analysis. H.A.V. and W.S. performed experiments with $\mathrm{PB}$ and tissue cells and analyzed the data and performed the HCMV transcriptome analysis. C.R.A.S. collected and processed PB and tissues from HCMV-exposed mice. A.B. performed immunofluorescence staining of animals. W.H.H. helped conceive and design experiments. P.A.D., R.S.B., N.J.M. and N.G. conceived and designed experiments and contributed to data interpretation, data presentation and manuscript writing. R.J.P. provided stocks of RSV-GFP; performed the immunofluorescent analysis of tissues sections for RSV infection and AB-PAS staining, and the analysis of human lung implant structures; conceived and designed experiments; and contributed to data interpretation, data presentation and manuscript writing. M.B. processed and cultured tissue homogenate to determine the number of the BCG c.f.u. and the analyzed data; conceived and designed experiments; and contributed to data interpretation, data presentation and manuscript writing. J.V.G. conceived and designed experiments and contributed to data interpretation, data presentation and manuscript writing; and conceived, designed and coordinated the study, the preparation of the manuscript and its revision

\section{Competing interests}

P.A.D. is an inventor of the acoustic angiography imaging technique, and a cofounder of SonoVol, Inc., a company that has licensed this patent.

\section{Additional information}

Supplementary information is available for this paper at https://doi.org/10.1038/ s41587-019-0225-9.

Reprints and permissions information is available at www.nature.com/reprints. Correspondence and requests for materials should be addressed to A.W. or J.V.G.

Publisher's note: Springer Nature remains neutral with regard to jurisdictional claims in published maps and institutional affiliations.

(c) The Author(s), under exclusive licence to Springer Nature America, Inc. 2019 


\section{Methods}

Ethics statement. Animal studies were carried out according to protocols approved by the Institutional Use and Care Committee at the University of North CarolinaChapel Hill and in adherence to the National Institutes of Health Guide for the Care and Use of Laboratory Animals.

Generation of humanized mice. LoM were constructed by implanting two pieces $\left(\sim 2-4 \mathrm{~mm}^{3}\right)$ of human fetal lung tissue (Advanced Bioscience Resources) subcutaneously into the back (right and left back or upper and lower back) of 13-18-week-old male and female NOD.Cg-Prkdc ${ }^{\text {scid }} 112 \mathrm{rg}^{\mathrm{tm} 1 \mathrm{Wjl}} / \mathrm{SzJ}$ mice (NSG mice; The Jackson Laboratory), creating two separate human lung implants. Engraftment and expansion of the human lung implants was monitored by palpation. After 12 weeks postimplantation, the lung implants are readily palpable under the skin of the mice and easy to manipulate for experiments. The lung implants persist for at least 12 months postimplantation (last time point analyzed). BLT-L mice were constructed by implanting a sandwich of human fetal thymus-liver-thymus tissue (Advanced Bioscience Resources) under the kidney capsule of irradiated (200 rad) 10-15-week-old male and female NSG mice. Two pieces of autologous human lung tissue $\left(\sim 2-4 \mathrm{~mm}^{3}\right)$ were implanted subcutaneously into the right and left back. Following tissue implantation, animals received a bone marrow transplant (via tailvein injection) of autologous liver-derived human $\mathrm{CD}^{+} 4^{+}$hematopoietic stem cells The non-CD34+ ${ }^{+}$cell fraction was used for four-digit HLA typing at the HLA-A, $B$ and C loci. Reconstitution of BLT-L mice with human hematopoietic cells was monitored longitudinally by flow cytometry as previously described ${ }^{13,14,62-64}$. Mice were maintained by the Division of Comparative Medicine at the University of North Carolina-Chapel Hill.

Ultrasound imaging. Two forms of 3D ultrasound imaging using Vevo 770 (version V3.0.0, VisualSonics) acquisition software were performed: B-mode, which is sensitive to different tissue types, and acoustic angiography, which is sensitive to microvasculature. B-mode imaging was used to assess implant volume, while acoustic angiography was performed to visualize implant vasculature. Acoustic angiography has been described in detail previously ${ }^{35,36}$. For imaging, LoM ( $n=6$ mice, 12 human lung implants, $24-35$ weeks postsurgery) were anesthetized with vaporized isoflurane (maintained at $2.0-2.5 \%$ ), the animal's side and back were depilated with a hair-removal cream (Nair) and the ultrasound transducer was coupled to the skin with gel. For acoustic angiography imaging, a microbubble contrast agent diluted in saline was administered intravenously through a tail-vein catheter. The lipid-shelled, perfluorocarbon core microbubble contrast agent used here is standard for ultrasound imaging and has been described in this application previously ${ }^{65}$. Rendering in 3D was performed with Slicer (version 4.8.1)

Human lung implant volume measurement. All image processing and analyses were performed in MATLAB R2017b (version 9.3.0.713579, Mathworks). Implant volume was measured from $3 \mathrm{D}$ B-mode ultrasound images as follows. First, the center slice of the implant was identified in all three orthogonal planes, and the dimensions of the implant were measured in each central slice, resulting in two measurements of each dimension. The two independent measurements were then averaged to obtain the three orthogonal dimensions (that is, diameters) of the implant. Implant volume was approximated as that of an ellipsoid of the same size, given by $V=\frac{4}{3} \pi a b c$, where $a, b$ and $c$ are equal to one-half of the orthogonal dimensions measured.

Immunohistochemical analysis. Immunohistochemical analyses were performed as previously described ${ }^{14,63,64,66}$. Briefly, human lung tissue and tissues collected from NSG, LoM and BLT-L mice were fixed in $4 \%$ paraformaldehyde (PFA) or $10 \%$ formalin, paraffin embedded and cut into $5 \mu \mathrm{m}$ sections. Before primary antibody incubation, antigen retrieval was performed and Ig-binding sites and endogenous peroxidase activity blocked. Tissue sections were developed using the MACH-3 polymer system (BioCare Medical) and 3,3' -diaminobenzidine (DAB) (Vector Laboratories), counterstained with hematoxylin and mounted. Immunofluorescence staining was also performed on 4\% PFA or formalin-fixed, paraffin-embedded tissue sections. Following antigen retrieval and blocking with 5\% serum (corresponding to the secondary antibody's host species), $0.1 \%$ Triton X-100 and 50\% Rodent M block (BioCare Medical) in PBS, tissue sections were incubated with primary antibodies overnight at $4^{\circ} \mathrm{C}$. Tissue sections were then stained with fluorescent conjugated secondary antibodies followed by DAPI and then mounted. Primary antibodies were directed against human epithelial cells (cytokeratin 19), endothelial cells (CD34), mesenchymal cells (vimentin), hematopoietic cells (CD45), macrophages (CD68), dendritic cells (CD11c), NK cells/NK T cells (CD56), B cells (CD20), T cells (CD3), CD4 ${ }^{+}$cells (CD4) and CD8 ${ }^{+}$cells (CD8) (Life Sciences Reporting Summary). Primary antibodies directed against mouse endothelial cells (mCD34), epithelial cells (mcytokeratin 19) and hematopoietic cells (mCD45) were used to distinguish the presence of mouse cells (Life Sciences Reporting Summary). Primary antibodies directed against HCMV glycoprotein B, IE, early and late proteins were used to detect HCMV-positive cells (Life Sciences Reporting Summary). Tissue sections were stained with an anti-ZIKV NS2B antibody to detect ZIKV-infected cells. Small pieces of human lung implant tissue collected from MERS-CoV-infected
LoM were fixed in $10 \%$ formalin for $>7 \mathrm{~d}$ at $4{ }^{\circ} \mathrm{C}$, embedded in paraffin, sectioned $(5 \mu \mathrm{m})$ and stained with MERS-CoV nucleocapsid polyclonal antibody (Life Sciences Reporting Summary). Tissue sections were also stained with appropriate isotype-negative control antibodies. Tissue sections for immunohistochemistry were imaged on a Nikon Eclipse Ci microscope using Nikon Elements BR software (version 4.30.01) with a Nikon Digital Sight DS-Fi2 camera and brightness and contrast were adjusted on whole images in Adobe Photoshop (CS6). Tissue sections for immunofluorescence were imaged on an Olympus BX61 upright wide-field microscope using Improvision's Velocity software (version X) with a Hammatuse ORCA RC camera. Brightness and contrast were adjusted on whole images using Image J software (version 1.51C). In Fig. 2b,d,h,m, pseudocoloring was used to depict MERS-CoV, ZIKV, RSV and HCMV antigens in green and human cell types in magenta. In Figs. 1i,j and $2 \mathrm{i}$ and Supplementary Fig. 1b, where red/green fluorescent images were originally captured, the red fluorescent signal was digitally altered to improve visualization by color-blind readers by adjusting the red channel hue by -45 using Adobe Photoshop (CS6).

Analysis of human immune cell reconstitution. Human immune cell reconstitution in the PB and tissues of BLT-L mice were analyzed by flow cytometry. Mononuclear cells (MNCs) were isolated from tissues collected from BLT-L mice by passage through a cell strainer and red blood cell lysis as previously described $^{13,14,62-64}$. The human lung implants, mouse lung, liver and female reproductive tract were enzymatically digested before passing tissue through a cell strainer. Liver and mouse lung MNCs were purified with a Percoll gradient. MNCs were isolated from the gastrointestinal tract (small and large intestines) lamina propria layer with an enzymatic digest as previously described. Before antibody (Life Sciences Reporting Summary) incubation Ig-binding sites were blocked. The antibody panels were as follows: CD45-APC, CD19-PE, CD3-FITC and CD4-PerCP (panel 1); CD45-APC, CD19-PE-Cy7, CD33-PE, CD3-FITC, CD4-APC-H7 and CD8-PerCP (panel 2); CD45-APC, CD19-PE-Cy7, CD33-PE, CD3-FITC and CD8-APC-Cy7 (panel 3); CD45-V500, CD3-AlexaFlour 700 or APC-R700, CD4-BV605, CD8-APC-Cy7, CD45RO-FITC or negative control mouse IgG2ak-FITC, CD69-PE or negative control mouse IgG1k, CCR7-PE-Cy7 or negative control rat IgG2aak, HLA-DR-PerCP or negative control mouse IgG2ak-PerCP, and CD25-APC or negative control mouse IgG1k-APC (panel 4); and CD45-V500, CD19-PE-Cy7, CD3-AlexaFlour 700 or APC-R700, CD4-APC-H7, CD8-FITC, CD45RA-Pacific Blue or negative control mouse IgG1ak-Pacific Blue, CD27-PE or negative control mouse IgG1k-PE, HLA-DR-PerCP or negative control mouse IgG2ak-PerCP, and CD38-APC or negative control mouse IgG1kAPC (panel 5). Following antibody incubation, PB was treated with 1X BD FACS lysing solution (BD Biosciences) to remove red blood cells. Samples were then washed and fixed with PFA. Data were acquired on a BD LSRFortessa or FACSCanto instrument and analyzed with FACSDiva software (version 6.1.3).

Analysis of human cytokine/chemokine production. MNCs were isolated from BLT-L mouse ( $n=6$ mice and 12 lung implants, data represent two experiments) human lung implants. Human lung implants were enzymatically digested before passing tissue through a cell strainer and MNCs were purified with a Percoll gradient. MNCs were pooled from the lung implants of 3 mice $(n=6$ lung implants) and cultured $\left(7.8 \times 10^{5}\right.$ cells per well of a 48 -well plate) for $4 \mathrm{~h}$ in RPMI supplemented with $10 \%$ FBS and $1 \%$ penicillin/streptomycin (untreated control, 1 well per experiment) or media supplemented with PMA (25 $\left.\mathrm{ng} \mathrm{m}^{-1}\right)$ / Ionomycin (250 $\left.\mathrm{ng} \mathrm{ml}^{-1}\right)$ ( 1 well experiment 1 , and 2 wells experiment 2$)$ or with LPS (100 $\mathrm{ng} \mathrm{ml}^{-1}$, E. coli O55:B5, Sigma) (1 well per experiment). Cell culture supernatant was collected at $4 \mathrm{~h}$. Cells were also isolated from the human lung implant of LoM ( $n=1$ mouse, 2 human lung implants, represents one experiment) following a $24 \mathrm{~h}$ enzymatic digest ( $1 \%$ Protease XIV/0.01\% DNase solution diluted 1:19 in F12 medium supplemented with amphotericin and gentamicin $)$ at $4^{\circ} \mathrm{C}$. Cells $\left(1 \times 10^{6}\right.$ cells per well) were cultured overnight in bronchial epithelial growth medium $(B E G M)^{67}$ supplemented with $10 \%$ FBS in wells of a collagen-coated 48-well plate $\left(5.6 \mu \mathrm{g} \mathrm{cm}^{-2}\right.$ human placental collagen type IV). Wells were washed to remove nonadherent cells and then cells cultured in BEGM $+10 \%$ FBS medium alone (untreated control) or supplemented with LPS (100 $\mathrm{ng} \mathrm{ml}^{-1}$, E. coli O55:B5, Sigma) ( 3 wells per condition/lung implant). Cell culture supernatant was collected at $24 \mathrm{~h}$. Plasma was isolated from PB collected from BLT-L mice $(n=10$ mice, represents three experiments) $3 \mathrm{~d}$ before and $4 \mathrm{~d}$ post-HCMV-TB40/E $\left(2.2 \times 10^{6}\right.$ tissue culture infectious dose (TCID) $)_{50}$ ) inoculation into human lung implants. Human cytokine/ chemokine levels in cell culture supernatant and plasma were measured using a Milliplex MAP kit (Millipore no. HCYTMAG-60K-PX41, limit of detection: $3.2 \mathrm{pg} \mathrm{ml}^{-1}$ ) on a Luminex MagPix instrument. Samples were run undiluted in singular wells. The following 41 human analytes were measured: Eotaxin/CCL11, FGF-2, Flt-3 ligand, Fractalkine, G-CSF, GM-CSF, GRO, IFN- $\alpha 2$, IFN- $\gamma$, IL- $1 \alpha$, IL-1 $\beta$, IL-1r $\alpha$, IL-2, IL-3, IL-4, IL-5, IL-6, IL-7, IL-8, IL-9, IL-10, IL-12 (p40), IL-12 (p70), IL-13, IL-15, IL-17A, IP-10, MCP-1, MCP-3, MDC (CCL22), MIP-1 $\alpha$, MIP$1 \beta$, PDGF-AA, PDGF-AB/BB, RANTES, sCD40L, TGF- $\alpha$, TNF- $\alpha$, TNF- $\beta$, VEGF and EGF. BEGM contains human EGF; therefore, EGF levels were not reported.

MERS-CoV production and analysis of infection. Stocks of the wild-type HCoVEMC/2012 of MERS-CoV (originally provided by Dr. Bart Haagmans, Erasmus 
Medical Center, Rotterdam, the Netherlands at passage 8) were prepared and virus titers determined on Vero CCL81 cells (American Type Culture Collection) under Biosafety Level 3 conditions as previously described ${ }^{1}$. MERS-CoV $\left(10^{4}\right.$ or $10^{5} \mathrm{PFU}$ per human lung implant) was inoculated in the human lung implants of anesthetized LoM via direct injection $(50 \mu$ l volume $)$ and human lung implants collected at $48 \mathrm{~h}$ postinfection ( $10^{4} \mathrm{PFU}: n=2$ mice, 4 human lung implants and data represent one experiment, $10^{5}$ PFU: $n=4$ mice, 8 human lung implants and data represent two experiments). To determine tissue MERS-CoV titers, pieces of human lung implant were weighed, homogenized and then stored at $-80^{\circ} \mathrm{C}$.

ZIKV production and analysis of infection. Stocks of ZIKV strain H/PF/2013 were prepared on Vero CCL81 cells (American Type Culture Collection). Virus titers were determined by quantifying the number of ZIKV RNA copies with real time PCR (3,208 ZIKV RNA copies per FFU based on real-time PCR analysis of ZIKV stocks titered on Vero CCL81 cells as previously described ${ }^{68}$ ). The human lung implants of LoM were injected with $10^{4}$ or $10^{3} \mathrm{FFU}$ ZIKV $(n=2 \mathrm{LoM}$, 4 human lung implants, per dose and data represent one experiment) (100 $\mu \mathrm{l}$ volume per implant). Mice were necropsied $48 \mathrm{~h}$ postinoculation. Human lung implants were processed into a single-cell suspension as described above. Cellassociated ZIKV RNA levels were measured using a quantitative real-time PCR assay using TaqMan RNA-to-CT 1-step kit (Applied Biosystems). The sequences of the forward and reverse primers and the TaqMan probe for PCR amplification and detection of ZIKV RNA were: 5' -CCGCTGCCCAACACAAG-3',

5'-CCACTAACGTTCTTTTGCAGACAT- $3^{\prime}$ and 5'-FAM-AGCCTACCT/ZEN/ TGACAAGCAGTCAGACACACTCAA-Q- ${ }^{\prime}$, respectively ${ }^{69}$.

BCG production and analysis of infection. $M$. bovis BCG Pasteur was grown at $37^{\circ} \mathrm{C}$ in liquid Middlebrook 7H9 medium supplemented with $0.05 \%$ Tween 80 , $0.5 \%$ glycerol and $1 \mathrm{X}$ albumin-dextrose-saline $(>0.5 \%$ bovine serum albumin, $0.2 \%$ glucose, $0.85 \% \mathrm{NaCl}$ ). The human lung implants of anesthetized LoM were injected with $4 \times 10^{4}$ or $4 \times 10^{2}$ c.f.u. BCG ( $n=3$ LoM, 3 human lung implants, per dose and data represent one experiment) ( $100 \mu$ l volume per lung implant). Mice were necropsied $28 \mathrm{~d}$ postexposure. At necropsy, one-half of each human lung implant was homogenized in PBS supplemented with $0.05 \%$ Tween $80,100 \mathrm{ng} \mathrm{ml}^{-1}$ cycloheximide and $50 \mu \mathrm{g} \mathrm{ml}^{-1}$ carbenicillin. The diluted homogenate was then plated onto $7 \mathrm{H} 10$-albumin-dextrose-saline-glycerol plates with $10 \mathrm{mg} \mathrm{ml}^{-1}$ cycloheximide for c.f.u. enumeration. The total number of c.f.u. per human lung implant was calculated by multiplying the number of c.f.u. $\times 2$. To visualize $B C G$, a LoM injected with $10^{5}$ c.f.u. BCG via intra-human lung injection ( $100 \mu$ l volume) was necropsied $28 \mathrm{~d}$ postexposure and small pieces of human lung implant tissue were fixed in $4 \%$ PFA, paraffin embedded and sectioned $(5 \mu \mathrm{m})$. Ziehl-Neelsen acid-fast staining was performed with carbol fuchsin and methylene blue. Tissue sections were imaged on an Olympus BX61 microscope with a RETIGA 4000R camera and brightness and contrast adjusted in Adobe Photoshop (CS6).

RSV production and analysis of infection. Recombinant RSV strain A2 expressing GFP has been previously described ${ }^{70}$. RSV $\left(2.5 \times 10^{5}\right.$ tissue culture infectious units per human lung implant) was directly injected $(100 \mu \mathrm{l}$ volume $)$ into the human lung implants of anesthetized LoM ( $n=3$ mice, 6 human lung implants and data represent two experiments). At necropsy ( $4 \mathrm{~d}$ postexposure), human lung implants were collected, enzymatically digested and passed through a cell strainer. RSV infection and replication were evaluated by measuring GFP expression with flow cytometry. Data were collected on a BD LSRFortessa instrument and analyzed with BD FACSDiva software (version 6.1.3). For immunofluorescence, paraffin-embedded tissue sections were probed with an anti-RSV antibody and an anti-cytokeratin 19 antibody or anti- $\beta$-tubulin IV antibody (Life Sciences Reporting Summary) to detect cilia of ciliated cells. Club cells were detected with an anti-CC10 antibody. Alcian-blue periodic acid-Schiff (AB-PAS) staining was performed to analyzed mucus production in human lung implants of naive control and RSV-infected LoM. Sections were imaged on an Olympus BX61 upright widefield microscope with a Hammatuse ORCA RC camera, an Olympus VS120 virtual slide scanning system with an Allied Vision Pike 5 CCD progressive scan camera or a Leica DM IRB epifluorescent microscope with a Q-Imaging Retiga Camera. Image acquisition was performed using Improvision's Volocity (version 6.3) or Q-Imaging Q Capture software (version 2.81) and brightness/contrast adjusted on whole images using ImageJ software (version 1.51C).

HCMV production and infection of mice. Anesthetized LoM and BLT-L mice were exposed to HCMV by direct injection of HCMV TB40/E $\left(4.25 \times 10^{5}-6 \times 10^{6}\right.$ $\left.\mathrm{TCID}_{50}\right)^{45,71}, \operatorname{ADrUL131}\left(2.4 \times 10^{5} \mathrm{TCID}_{50}\right)^{48}$ or AD169 $\left(1.1-6 \times 10^{6} \mathrm{TCID}_{50}\right)^{72}$ into the human lung implants. For the TB40/E time course experiment in LoM, human lung implants were collected at days 4 ( $n=2$ mice, 4 human lung implants), 7 ( $n=2$ mice, 4 human lung organoids), 14 ( $n=3$ mice, 5 human lung implants) and 21 ( $n=2$ mice, 3 human lung implants) postexposure and data represent one experiment. The TB40/E-infected human lung implant analyzed at $52 \mathrm{~d}$ postexposure in Fig. 21 represents an additional LoM. For the GCV preexposure prophylaxis experiment, LoM ( $n=3$ mice, 6 human lung implants) were administered $100 \mathrm{mg} \mathrm{kg}^{-1} \mathrm{GCV}$ daily for $17 \mathrm{~d}$ by intraperitoneal injection and inoculated with HCMV TB40/E expressing luciferase $\left(4.25 \times 10^{5} \mathrm{TCID}_{50}\right)^{45}$ after two GVC doses. Untreated LoM ( $n=5$ mice, 7 human lung implants) inoculated with HCMV TB40/E expressing luciferase $\left(4.25 \times 10^{5} \mathrm{TCID}_{50}\right)$ served as a control. Luciferase expression was measured on anesthetized mice with an IVIS Lumina Optical System following intraperitoneal injection of D-Luciferin $\left(15 \mathrm{mg} \mathrm{kg}^{-1}\right)$ on days $4,11,14,21$ and 25 postexposure. For the AD169 time course experiment in LoM, human lung implants were collected at days 4 ( $n=2$ mice, 3 human lung implants), 7 ( $n=2$ mice, 4 human lung organoids), 14 ( $n=2$ mice, 4 human lung implants), 21 ( $n=2$ mice, 4 human lung implants) and 28 ( $n=2$ mice, 4 human lung implants) postexposure and data represent one experiment. To evaluate HCMV replication over time in human lung implants, HCMV TB40/E expressing luciferase $\left(4.25 \times 10^{5} \mathrm{TCID}_{50}\right)^{45}$ was inoculated into the human lung implants of human donor matched LoM ( $n=3$ mice, 6 human lung implants) and BLT-L mice ( $n=3$ mice, 6 human lung implants). Luciferase expression was measured on anesthetized mice with an IVIS Lumina Optical System following intraperitoneal injection of D-Luciferin $\left(15 \mathrm{mg} \mathrm{kg}^{-1}\right)$ on days $4,7,11$ and 14 and weeks 4 and 5 following HCMV exposure. Baseline luminescence in human lung implants was determined in LoM and BLT-L mice before HCMV exposure. Data represent one experiment in LoM and BLT-L mice. To evaluate the HCMV-specific immune response after multiple virus doses, BLT-L mice received three (administered 1 month and then 2 weeks apart) or four (administered 2 weeks apart) inoculations of HCMV TB40/E or AD169. Data represent five experiments. PB and tissues were collected from LoM and BLT-L mice and processed as described previously and above. In Fig. 2k, human lung implant cells isolated from TB40/E-infected LoM were also Percolled. HCMV DNA levels in PB and tissue cells were measured by real-time PCR analysis as previously described ${ }^{73}$.

HCMV transcriptome analysis. Total RNA was extracted from human lung implants collected from HCMV TB40/E-infected LoM using Trizol following tissue homogenization and combined. Data represent one experiment. Ribosomal RNA was depleted using RiboMinus (Thermo Fisher). (ds)cDNA was generated from rRNA-depleted total RNA using the SMARTer PCR cDNA synthesis kit (Takara). Viral-specific (ds)cDNA was then captured using custom-designed biotinylated probes spanning both strands of the entire HCMV genome (Agilent). After extensive washing, the bound (ds)cDNA was eluted from the capture probes, and next generation sequencing libraries were generated from the eluted (ds)cDNA using the Nextera XT trans-fragmentation kit (Illumina). The resulting library was sequenced on an Illumina HiSeq 2500 using $2 \times 100$ base pair paired-end reads. High-quality reads were aligned to the HCMV genome, and viral expression was quantified in reads per kilobase per million using Cuffdiff (Cufflinks, version 2.2.1).

Detection of IgM and IgG antibodies to HCMV. Antibodies to HCMV in plasma were measured using either an HCMV IgM or IgG enzyme immunoassay test kit (Genway). HCMV IgM or IgG Index = average optical density of triplicate samples/ (calibrator optical density $\times$ lot-specific Calibrator Factor), as per manufacturer's protocol. Randomly selected samples were re-run to assess intra-assay variability. All tests showed low inter- and intra-assay variability $(<10 \%$ coefficient of variation). A seropositive sample was designated as having either an HCMV IgM or IgG index $>$ measured index from naïve BLT-L mice $(n=5)$. To analyze the HCMV neutralizing activity in plasma of HCMV-exposed BLT-L mice, the plasma of a naïve BLT-L mouse $(n=1)$ and BLT-L mice exposed repeatedly to TB40/E (3-4 times, $n=6$ mice) was heated at $56^{\circ} \mathrm{C}$ for $15-20 \mathrm{~min}$ then diluted $1: 60$ in DMEM/F12 medium supplemented with 10\% FBS (heat-inactivated) and 1\% penicillin/streptomycin. Diluted plasma was incubated with HCMV-TB40/E-RFP for $1 \mathrm{~h}$ at $37^{\circ} \mathrm{C}$. The virus mixture was added to ARPE-19 cells (multiplicity of infection 5) in quadruplicate wells of a 24 -well plate and incubated for $2 \mathrm{~h}$ at $37^{\circ} \mathrm{C}$ at which time virus containing medium was removed and fresh medium added. After $72 \mathrm{~h}$, cells were fixed, stained with DAPI and the number of $\mathrm{RFP}^{+}$cells counted. Data represent one in vitro infection experiment.

Human antigen-presenting cell (APC) production. Autologous human B-lymphoblastoid cell lines (BLCLs) or mDCs were generated from each human tissue donor analyzed (eight donors total) and used as APCs in ELISpot and ICS assays. BLCLs were derived from the human fetal liver CD34-negative fraction or from human $\mathrm{CD} 19^{+}$cells positively selected from BLT-L tissue cells using CD19 microbeads (Miltenyi), following the manufacturer's instructions. Cells were infected with EBV B95-8 overnight and maintained at $37^{\circ} \mathrm{C}$ until transformation (8-10 weeks later). BLCLs were propagated in RPMI 1640 with $10 \%$ FBS. mDCs were generated from human fetal liver-derived CD $34^{+}$cells magnetically selected using CD34 microbeads (Miltenyi). Purified CD34 ${ }^{+}$cells were plated at a concentration of $1 \times 10^{6}$ cells per $\mathrm{ml}$ in IMDM medium supplemented with $10 \%$ FBS, $100 \mathrm{ng} \mathrm{ml}^{-1}$ GM-CSF, $2.5 \mathrm{ng} \mathrm{ml}^{-1}$ TNF- $\alpha, 50 \mathrm{ng} \mathrm{ml}^{-1}$ Flt-3L, $2.5 \mathrm{ng} \mathrm{ml}^{-1}$ SCF and $10 \mathrm{ng} \mathrm{ml}^{-1} \mathrm{IL}-4$ (R\&D Systems). Medium was refreshed every $3 \mathrm{~d}$. Maturation of DCs was initiated $3 \mathrm{~d}$ before planned T-cell assays using IMDM supplemented with $10 \%$ FBS, $800 \mathrm{U} \mathrm{ml}^{-1}$ GM-CSF, $10 \mathrm{ng} \mathrm{ml}^{-1} \mathrm{TNF}-\alpha, 1 \mu \mathrm{g} \mathrm{ml}^{-1} \mathrm{PEG}-2,10 \mathrm{ng} \mathrm{ml}^{-1}$ $\mathrm{IL}-1 \beta, 400 \mathrm{U} \mathrm{ml}^{-1} \mathrm{IL}-4$ and $100 \mathrm{ng} \mathrm{ml}^{-1}$ IL-6 (R\&D Systems). Autologous BLCLs (CD19-PerCP positive) or mDCs (CD11c-PE positive) were phenotyped by flow cytometry using the following antibodies: pan-HLA-I Class-Pacific Blue, HLAE-PE and HLA-DR-PE-Cy7; or CD80-PE-Cy7, CD83-APC and CD86-PE-Cy7, 
respectively (Life Sciences Reporting Summary). For APC irradiation and peptide pulsing, peptides were synthesized by Sigma-Genosys. Autologous BLCLs or matured mDCs were irradiated $(5,000 \mathrm{rad})$, then pulsed for $60 \mathrm{~min}$ at $37^{\circ} \mathrm{C}$ with either individual peptides $(1-2.5 \mu \mathrm{g})$ or a pool of 69 overlapping peptides (12-18 amino acids overlapping by 10 amino acids) spanning the CMV IE1 protein $(0.5 \mu \mathrm{g}$ of each peptide) for $60 \mathrm{~min}$. Cells were then washed 3 times and counted before adding to T-cell assays. The individual peptides used in these studies include pp65 ${ }_{(495-504)}$ NLVPMVATV $\left(A^{\star} 02: 01\right)$ and pp65 ${ }_{(123-131)}$ IPSINVHHY (B*35:01).

Ex vivo IFN- $\boldsymbol{\gamma}$ ELISpot assay. BLT-L tissue cells $\left(3 \times 10^{5}\right)$ were cocultured with peptide-pulsed, autologous BLCL in a $1: 2$ ratio in $200 \mu \mathrm{l}$ for $18-20 \mathrm{~h}$ at $37^{\circ} \mathrm{C} / 5 \%$ $\mathrm{CO}_{2}$. Assays were performed in triplicate or quadruplicate. Tissue cells cocultured with mock-pulsed BLCLs served as a negative control and tissue cells cocultured with $50 \mathrm{ng} \mathrm{ml}^{-1} \mathrm{PMA}+500 \mathrm{ng} \mathrm{ml}^{-1}$ Ionomycin served as a positive control. ELISpot assay development and spot counting were performed as described previously ${ }^{74}$. ELISpot data were expressed as the mean spot forming units (SFU) per million CD3-positive T cells \pm s.e.m. Positive T-cell responses were defined as those $>50$ SFU per million CD3 T cells and $\geq 2 \times$ mean of negative control wells. While not a criterion for positivity, across all assays in all cohorts, the average of the mockpulsed BLCLs was 24.6 SFU per input cells, as detailed in Supplementary Table 5.

ICS. Peptide-pulsed autologous BLCL (2:1) or mDCs (1:10) were irradiated $(5,000 \mathrm{rad})$ then combined with filtered $(0.45 \mu \mathrm{m})$, total or CD8-microbead (Miltenyi)-selected tissue suspensions (minimum, $1 \times 10^{6}$ cells). Panels measured either (A) IFN- $\gamma /$ CD107a or (B) IFN- $\gamma /$ TNF- $\alpha$. (A) For measurement of IFN- $\gamma$ / CD107a, cocultures were immediately stained with CD107a-APC, monensin added, then cultured for $6 \mathrm{~h}$ or overnight at $37^{\circ} \mathrm{C}, 5 \% \mathrm{CO}_{2}$. Next, cells were stained with Zombie NIR viability dye at room temperature for $20 \mathrm{~min}$, then labeled with CD3-BV421; CD4-BV650; CD8-BV510; and PerCP-conjugated $\mathrm{CD} 14,16,19$ and 56 (dump channel) at room temperature for $15 \mathrm{~min}$. Cells were fixed, permeabilized and stained intracellularly with IFN- $\gamma$-PE. (B) For detection of IFN- $\gamma /$ TNF- $\alpha$, monensin/Brefeldin A was added to cocultures, which were then incubated overnight at $37^{\circ} \mathrm{C}, 5 \% \mathrm{CO}_{2}$. The next day, cells were stained with Zombie NIR and lymphocyte markers described in (A) above. Cells were fixed, permeabilized and stained intracellularly with IFN- $\gamma$-FITC and TNF $\alpha$-PE/Dazzyle 594 (Life Sciences Reporting Summary). In all assays, fluorescence minus one controls were used for gating of CD107a, cytokine and CD8 reactive populations. For compensation, beads were used for all colors except Zombie. For Zombie, live and dead (heat-inactivated) cells were mixed and Zombie stained to generated positive and negative populations. All cells were acquired using an LSRFortessa flow cytometer and data analyzed with FlowJo software (version 10) (gating strategies illustrated in Supplementary Fig. 11a,b). T-cell responses were expressed as frequency of either $\mathrm{CD}^{+}$or $\mathrm{CD}^{+} \mathrm{T}$-cell lymphocytes. An HCMV-specific T-cell response met the following criteria: $>10,000 \mathrm{CD} 4$ - or CD8-positive events, $>0.01 \%$ of $\mathrm{CD}^{+}$or $\mathrm{CD}^{+} \mathrm{T}$ cells, a minimum of 10 events in the IFN- $\gamma / \mathrm{CD} 107 \mathrm{a}$ or IFN- $\gamma$ TNF- $\alpha$ double-positive gate, $2 \times$ no-peptide control.

Multimer reactivity. PE- or APC-conjugated pentamers (ProImmune) were used for staining of total or CD8-microbead- (Miltenyi Biotec) selected tissue (liver and/ or human lung) suspensions. In all assays, a minimum of $1 \times 10^{6}$ cells were used and cells were filtered $(0.45 \mu \mathrm{m})$ before staining. Cells were stained with Zombie 2 viability dye at room temperature for $20 \mathrm{~min}$, followed by staining with pentamer (as per manufacturer's instructions) at room temperature for $15 \mathrm{~min}$. After washing, CD3-BV421; CD4-BV650; CD8-BV510; and PerCP-conjugated CD14, 16, 19 and 56 (dump channel) were added and cells incubated on ice for $15 \mathrm{~min}$. Cells were washed and fixed. All cells were acquired using an LSRFortessa flow cytometer and data analyzed with FlowJo software (version 10) (gating strategy illustrated in Supplementary Fig. 11c). A pentamer reactive population met the following criteria: $>3,000$ CD8-positive events, greater than $2 \times$ control pentamer (HLA-mismatched, non-HCMV), greater than $0.01 \%$ of all $\mathrm{CD}^{+} \mathrm{T}$ cells, $>10$ events in the pentamer gate and no evidence of nonspecific staining in non-CD8 ${ }^{+} \mathrm{T}$-cell gates.

Statistical analyses. The statistical test used is indicated below and in the figure legends and/or the Results. The definition of center and dispersion and precision measures are indicated in the figure legends and/or the Results. The exact value of $n$ and what $n$ stands for is in the figure legends and Methods details. Statistical analyses were performed in GraphPad Prism (version 6, 7 or 8) or R (version 3.4.4). No statistical methods were used to predetermine sample size. No randomization was used to determine how samples/animals were allocated to experimental groups or processed. Investigators were not blinded to group allocations or when assessing outcomes. For all statistical comparisons $P<0.05$ was considered significant. All statistical tests were exact. A two-tailed Mann-Whitney test was used to compare luciferase activity in the human lung implants of LoM and BLT-L mice (Fig. 4a) and human immune cell levels in the mouse lung and human lung organoids of BLT-L mice (Supplementary Fig. 6). A two-tailed Fischer's exact test was used to compare the incidence of HCMV-specific human IgM, IgG and CD8 ${ }^{+} \mathrm{T}$ cells in BLT-L mice exposed to one or multiple doses of HCMV (Figs. 4 and 5). Human cytokine and chemokine levels pre- and post-HCMV inoculation were compared with a two-tailed Wilcoxon matched-pairs signed rank test (Supplementary Fig. 8).

Reporting Summary. Further information on research design is available in the Nature Research Reporting Summary linked to this article.

\section{Data availability}

The data generated are available from corresponding authors on reasonable request.

\section{References}

62. Sacre, K. et al. Expansion of human cytomegalovirus (HCMV) immediateearly 1-specific CD8 ${ }^{+} \mathrm{T}$ cells and control of HCMV replication after allogeneic stem cell transplantation. J. Virol. 82, 10143-10152 (2008).

63. Honeycutt, J. B. et al. Macrophages sustain HIV replication in vivo independently of T cells. J. Clin. Invest. 126, 1353-1366 (2016).

64. Olesen, R. et al. ART influences HIV persistence in the female reproductive tract and cervicovaginal secretions. J. Clin. Invest. 126, 892-904 (2016)

65. Shelton, S. E. et al. Quantification of microvascular tortuosity during tumor evolution using acoustic angiography. Ultrasound Med. Biol. 41, 1896-1904 (2015).

66. Honeycutt, J. B. et al. HIV persistence in tissue macrophages of humanized myeloid-only mice during antiretroviral therapy. Nat. Med. 23, 638-643 (2017).

67. Fulcher, M. L., Gabriel, S., Burns, K. A., Yankaskas, J. R. \& Randell, S. H. Well-differentiated human airway epithelial cell cultures. Methods Mol. Med. 107, 183-206 (2005).

68. Zhang, S. et al. Neutralization mechanism of a highly potent antibody against Zika virus. Nat. Commun. 7, 13679 (2016).

69. Lanciotti, R. S. et al. Genetic and serologic properties of Zika virus associated with an epidemic, Yap State, Micronesia, 2007. Emerg. Infect. Dis. 14, 1232-1239 (2008).

70. Hallak, L. K., Spillmann, D., Collins, P. L. \& Peeples, M. E. Glycosaminoglycan sulfation requirements for respiratory syncytial virus infection. J. Virol. $\mathbf{7 4}$, 10508-10513 (2000).

71. O'Connor, C. M. \& Shenk, T. Human cytomegalovirus pUS27 G proteincoupled receptor homologue is required for efficient spread by the extracellular route but not for direct cell-to-cell spread. J. Virol. 85 3700-3707 (2011)

72. Wang, D., Bresnahan, W. \& Shenk, T. Human cytomegalovirus encodes a highly specific RANTES decoy receptor. Proc. Natl Acad. Sci. USA 101, 16642-16647 (2004).

73. Ziehr, B., Lenarcic, E., Cecil, C. \& Moorman, N. J. The eIF4AIII RNA helicase is a critical determinant of human cytomegalovirus replication. Virology 489, 194-201 (2016)

74. Goonetilleke, N. et al. Induction of multifunctional human immunodeficiency virus type 1 (HIV-1)-specific T cells capable of proliferation in healthy subjects by using a prime-boost regimen of DNA- and modified vaccinia virus Ankara-vectored vaccines expressing HIV-1 Gag coupled to CD8 ${ }^{+}$T-cell epitopes. J. Virol. 80, 4717-4728 (2006). 


\section{nature research}

Corresponding author(s): J. Victor Garcia

Last updated by author(s): Jul 3, 2019

\section{Reporting Summary}

Nature Research wishes to improve the reproducibility of the work that we publish. This form provides structure for consistency and transparency in reporting. For further information on Nature Research policies, see Authors \& Referees and the Editorial Policy Checklist.

\section{Statistics}

For all statistical analyses, confirm that the following items are present in the figure legend, table legend, main text, or Methods section. $\mathrm{n} / \mathrm{a}$ Confirmed

\ The exact sample size $(n)$ for each experimental group/condition, given as a discrete number and unit of measurement

\ A statement on whether measurements were taken from distinct samples or whether the same sample was measured repeatedly

$\triangle$ The statistical test(s) used AND whether they are one- or two-sided

Only common tests should be described solely by name; describe more complex techniques in the Methods section.

$\triangle \square$ A description of all covariates tested

Х $\square$ A description of any assumptions or corrections, such as tests of normality and adjustment for multiple comparisons

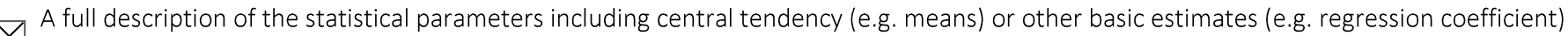

AND variation (e.g. standard deviation) or associated estimates of uncertainty (e.g. confidence intervals)

For null hypothesis testing, the test statistic (e.g. $F, t, r$ ) with confidence intervals, effect sizes, degrees of freedom and $P$ value noted

Give $P$ values as exact values whenever suitable.

Х $\square$ For Bayesian analysis, information on the choice of priors and Markov chain Monte Carlo settings

Х $\square$ For hierarchical and complex designs, identification of the appropriate level for tests and full reporting of outcomes

Х $\square$ Estimates of effect sizes (e.g. Cohen's d, Pearson's $r$ ), indicating how they were calculated

Our web collection on statistics for biologists contains articles on many of the points above.

\section{Software and code}

\section{Policy information about availability of computer code}

Data collection

Vevo 770 (version V3.0.0) acquisition ultrasound software, Nikon Elements BR software (version 4.30.01), Improvision's Volocity software (version 6.3), Quantitative Imaging Corp, QCapture (Version 2.81), BD FACSDiva software (version 6.1.3).

Data analysis

Adobe Photoshop (CS6), ImageJ software (version 1.51C), BD FACSDiva software (version 6.1.3), FlowJo software (version 10), Microsoft Excel (2016), GraphPad Prism (versions 6, 7 and 8), R (version 3.4.4) (Cufflinks (version 2.2.1), samtools (version 0.1.19), MATLAB R2017b (version 9.3.0.713579), Slicer (version 4.8.1).

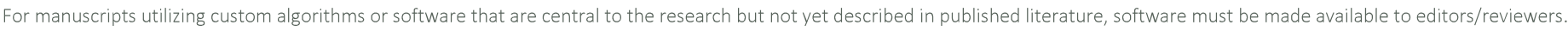
We strongly encourage code deposition in a community repository (e.g. GitHub). See the Nature Research guidelines for submitting code \& software for further information.

\section{Data}

Policy information about availability of data

All manuscripts must include a data availability statement. This statement should provide the following information, where applicable:

- Accession codes, unique identifiers, or web links for publicly available datasets

- A list of figures that have associated raw data

- A description of any restrictions on data availability 
Please select the one below that is the best fit for your research. If you are not sure, read the appropriate sections before making your selection.

$\bigotimes$ Life sciences $\quad \square$ Behavioural \& social sciences $\quad \square$ Ecological, evolutionary \& environmental sciences

For a reference copy of the document with all sections, see nature.com/documents/nr-reporting-summary-flat.pdf

\section{Life sciences study design}

All studies must disclose on these points even when the disclosure is negative.

Sample size No statistical methods were used to predetermine sample size. At least 3 samples were used for each group, the minimum to achieve statistical significance, unless otherwise noted.

Data exclusions No data were excluded from analysis.

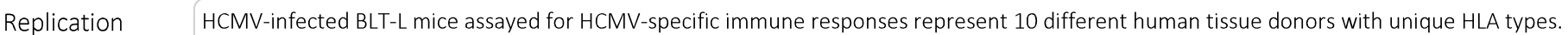
For the measurement of HCMV-specific IgM and IgG, randomly selected samples were re-run to assess intra-assay variability. All tests showed low inter- and intra-assay variability $(<10 \% \mathrm{CV})$. Samples assayed by Elispot for IFN- $\gamma$ were run in triplicate wells (all attempts at replication were successful).

Randomization No randomization was used to determine how samples/animals were allocated to experimental groups or processed. Groups of mice representing the same human donor were inoculated with the same HCMV strain so that cells from multiple mice could be combined for $T$ cell analyses if necessary.

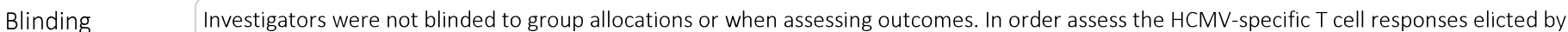
BLT-L mice, information regarding the HLA type of the mouse and infecting strain were needed to ensure that the appropriate reagents (e.g. pentamers, peptides, etc) were utilized in the assays. In addition, in some instances cells were pooled from multiple HLA-matched mice to evaluate HCMV-specific T cell responses (Figure 4D).

\section{Reporting for specific materials, systems and methods}

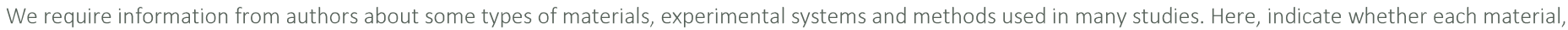

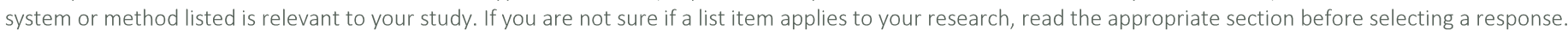

\begin{tabular}{|c|c|c|c|}
\hline \multicolumn{2}{|r|}{ Materials \& experimental systems } & \multicolumn{2}{|c|}{ Methods } \\
\hline $\mathrm{n} / \mathrm{a}$ & Involved in the study & $\mathrm{n} / \mathrm{a}$ & Involved in the study \\
\hline & Х Antibodies & Х & ChIP-seq \\
\hline $\mathbf{S}^{-1}$ & $\bigotimes$ Eukaryotic cell lines & & \ Flow cytometry \\
\hline$\bigotimes$ & Palaeontology & $\bigotimes$ & MRI-based neuroimaging \\
\hline & $\bigotimes$ Animals and other organisms & & \\
\hline Х & $\square$ Human research participants & & \\
\hline Х & $\square$ Clinical data & & \\
\hline
\end{tabular}

\section{Antibodies}

Antibodies used

List of Antibodies:

Antibodies were validated by the manufacturer with details in the links provided.

Flow Cytometry:

- anti-CD3-FITC (clone HIT3a) (3ul/test) BD Biosciences Cat \#555339 https://www.biolegend.com/it-it/products/purified-anti-

human-cd3-antibody-75

- anti-CD3-AlexaFluor ${ }^{\oplus} 700$ (clone UCHT1) (3ul/test) BioRad Cat \#MCA463A700 https://www.bio-rad-antibodies.com/

monoclonal/human-cd3-antibody-ucht1-mca463.html?f=purified

- anti-CD3-APC-R700 (clone UCHT1) (3ul/test) BD Biosciences Cat \#565119 http://www.bdbiosciences.com/us/reagents/

research/antibodies-buffers/immunology-reagents/anti-human-antibodies/cell-surface-antigens/apc-r700-mouse-anti-human-

cd3-ucht1-also-known-as-ucht-1-ucht-1/p/565119

- anti-CD4-APC-H7 (clone RPA-T4) (3ul/test) BD Biosciences Cat \#560158 http://www.bdbiosciences.com/us/applications/ research/t-cell-immunology/th-1-cells/surface-markers/human/apc-h7-mouse-anti-human-cd4-rpa-t4/p/560158

- anti-CD4-BV TM605 (clone RPA-T4) (3ul/test)BD Biosciences Cat \#562658 http://www.bdbiosciences.com/us/applications/ research/t-cell-immunology/th-1-cells/surface-markers/human/bv605-mouse-anti-human-cd4-rpa-t4/p/562658

- anti-CD8-PerCP (clone SK1) (3ul/test) BD Biosciences Cat \#347314 http://www.bdbiosciences.com/us/reagents/research/

clinical-research---ruo-gmp/single-color-antibodies/percp-mouse-anti-human-cd8-sk1/p/347314

- anti-CD8-APC-Cy7 (clone SK1) (3ul/test) BD Biosciences Cat \#557834 http://www.bdbiosciences.com/us/reagents/research/ 
antibodies-buffers/immunology-reagents/anti-human-antibodies/cell-surface-antigens/apc-cy7-mouse-anti-human-cd8-sk1/ $\mathrm{p} / 557834$

- anti-CD19-PE-Cy7 (clone SJ25C1) (3ul/test) BD Biosciences Cat \#557835 http://www.bdbiosciences.com/us/applications/ research/clinical-research/oncology-research/blood-cell-disorders/surface-markers/human/pe-cy7-mouse-anti-human-cd19sj25c1-also-known-as-sj25-c1/p/557835

- anti-CD25-APC (clone 2A3) (3ul/test) BD Biosciences Cat \#340938 http://www.bdbiosciences.com/us/applications/clinical/ blood-cell-disorders/asr-reagents/cd25-apc-2a3/p/340938

- anti-CD33-PE (clone P67.6) (3ul/test) BD Biosciences Cat \#340679 https://www.bdbiosciences.com/us/applications/research/ stem-cell-research/hematopoietic-stem-cell-markers/human/negative-markers/pe-mouse-anti-human-cd33-p676/p/347787 - anti-CD45-APC (clone HI30) (3ul/test) BD Biosciences Cat \#555485 http://www.bdbiosciences.com/eu/applications/research/ stem-cell-research/cancer-research/human/apc-mouse-anti-human-cd45-hi30/p/555485

- anti-CD45-V500 (clone HI30) (3ul/test) BD Biosciences Cat \#560777 http://www.bdbiosciences.com/us/applications/research/ stem-cell-research/cancer-research/human/v500-mouse-anti-human-cd45-hi30/p/560777

- anti-CD45RO-FITC (clone UCHL1) (3ul/test) BD Biosciences Cat \#555492 http://www.bdbiosciences.com/us/applications/ research/t-cell-immunology/regulatory-t-cells/surface-markers/human/fitc-mouse-anti-human-cd45ro-uchl1/p/555492

- anti-CD69-PE (clone FN50) (3ul/test) BD Biosciences Cat \#555531 http://www.bdbiosciences.com/us/applications/research/tcell-immunology/regulatory-t-cells/surface-markers/human/pe-mouse-anti-human-cd69-fn50-also-known-as-fn-50/p/555531 - anti-HLA-DR-PerCP (clone L243) (3ul/test) BD Biosciences Cat \#347364 http://www.bdbiosciences.com/us/applications/ research/stem-cell-research/mesenchymal-stem-cell-markers-bone-marrow/human/negative-markers/percp-mouse-antihuman-hla-dr-1243/p/347364

- anti-CCR7 (CD197)-PE-Cy7 (clone 3D12) (3ul/test) BD Biosciences Cat \#557648 https://www.bdbiosciences.com/us/ applications/research/t-cell-immunology/th-2-cells/surface-markers/human/pe-cy7-rat-anti-human-ccr7-cd197/p/557648 - anti-CD38-APC (HB7) (3ul/test) BD Biosciences Cat \#340439 http://www.bdbiosciences.com/us/applications/research/t-cellimmunology/regulatory-t-cells/surface-markers/human/apc-mouse-anti-human-cd38-hb7/p/340439

- anti-CD45RA-Pacific Blue (F8-11-13) (3ul/test) BioRad Cat \#MCA88PB https://www.bio-rad-antibodies.com/monoclonal/ human-cd45ra-antibody-f8-11-13-mca88.html?f=purified

- anti-CD27-PE (M-T271) (3ul/test) BD Biosciences Cat \#555441 http://www.bdbiosciences.com/us/applications/research/ clinical-research/oncology-research/blood-cell-disorders/surface-markers/human/pe-mouse-anti-human-cd27-m-t271/ $\mathrm{p} / 555441$

- anti-CD3-BV TM421 (UCHT1) (3ul/test) BD Biosciences Cat \#562426 http://www.bdbiosciences.com/us/applications/research/tcell-immunology/th-1-cells/surface-markers/human/bv421-mouse-anti-human-cd3-ucht1-also-known-as-ucht-1-ucht-1/ $\mathrm{p} / 562426$

- anti-CD4-AlexaFluor ${ }^{\circledR} 488$ (clone OKT4) (2uL per test) BioLegend Cat \#317420 https://www.citeab.com/ antibodies/522291-317420-alexa-fluor-488-anti-human-cd4-okt4-monocl

- anti-CD4-BV ${ }^{\mathrm{TM}} 650$ (clone OKT4) (1uL per test) BioLegend Cat \#317436 https://www.biolegend.com/en-us/products/brilliantviolet-650-anti-human-cd4-antibody-7786

- anti-CD8-BV TM510 (clone RPA-T8) (2ul per test) BioLegend Cat \#301048 https://www.biolegend.com/en-us/search-results/ brilliant-violet-510-anti-human-cd8a-antibody-8000

- anti-CD11c-APC (clone S-HCL-3) (2ul per test) BD Biosciences Cat \#333144 http://www.bdbiosciences.com/eu/reagents/ clinical/reagents/single-antibodies/cd11c-apc-s-hcl-3/p/333144

- anti-CD11C-PE (clone B-LY6) (2ul per test) BD Biosciences Cat \#555392 http://www.bdbiosciences.com/eu/reagents/research/ antibodies-buffers/immunology-reagents/anti-human-antibodies/cell-surface-antigens/pe-mouse-anti-human-cd11c-b-ly6/ $\mathrm{p} / 555392$

- anti-CD14-BV TM650 (clone M5E2) (2ul per test) BioLegend Cat \#301836 https://www.biolegend.com/en-us/products/brilliantviolet-650-anti-human-cd14-antibody-7819

- anti-CD14-PerCP (clone HCD14) (2ul per test) BioLegend Cat \#325632 https://www.biolegend.com/en-us/search-results/percpanti-human-cd14-antibody-9564

- anti-CD16-PerCP (clone 3G8) (2ul per test) BioLegend Cat \#302030 https://www.biolegend.com/en-us/search-results/percpanti-human-cd16-antibody-4340

- anti-CD19-PerCP (clone HIB19) (2ul per test) BioLegend Cat \#302228 https://www.biolegend.com/en-us/products/percp-antihuman-cd19-antibody-4225

- anti-CD56-PerCP (clone HCD56) (2ul per test) BioLegend Cat \#318342 https://www.biolegend.com/en-us/search-results/percpanti-human-cd56-ncam-antibody-8388

- anti-CD80-PE-Cy7 (clone L307.4) (1ul per test) BD Biosciences Cat \#561135 https://www.bdbiosciences.com/us/applications/ research/b-cell-research/surface-markers/human/pe-cy7-mouse-anti-human-cd80-13074-also-known-as-1307/p/561135 - anti-CD83-APC (clone HB15E) (3ul per test) BD Biosciences Cat \#551073 http://www.bdbiosciences.com/us/reagents/research/ antibodies-buffers/immunology-reagents/anti-human-antibodies/cell-surface-antigens/apc-mouse-anti-human-cd83-hb15e/ $\mathrm{p} / 551073$

- anti-CD86-PE-Cy7 (clone 2331 FUN-1) (1ul per test) BD Biosciences Cat \#561128 https://www.bdbiosciences.com/us/ applications/research/t-cell-immunology/regulatory-t-cells/surface-markers/human/pe-cy7-mouse-anti-human-cd86-2331fun-1/p/561128

- anti-CD107 $\alpha$-APC (clone H4A3) (1ul per test) BioLegend Cat \#328620 https://www.biolegend.com/fr-fr/products/apc-antihuman-cd107a-lamp-1-antibody-5428

- anti-IFN-Y-PE (clone 4S.B3) (3ul per test) BioLegend Cat \#502509 https://www.biolegend.com/en-us/products/pe-anti-humanifn-gamma-antibody-1011

- anti-IFN-y-FITC (clone 4S.B3) (5ul per test) BioLegend Cat \#502505 https://www.biolegend.com/en-us/products/fitc-antihuman-ifn-gamma-antibody-1013

- anti-TNF- $\alpha$-PE\Dazzle 594 (clone Mab11) (3ul per test) BioLegend Cat \#502946 https://www.biolegend.com/en-us/searchresults/pe-dazzle-594-anti-human-tnf-alpha-antibody-10268

- anti-HLA-A,B,C-PacificBlue (clone W6/32) (3ul per test) BioLegend Cat \#311418 https://www.biolegend.com/fr-ch/products/ pacific-blue-anti-human-hla-a-b-c-antibody-3336

- anti-HLA-DR-PE-Cy7 (clone L243) (1ul per test) BioLegend Cat \#307616 https://www.biolegend.com/en-us/products/pe-cy7anti-human-hla-dr-antibody-2862

- Mouse IgG1k Isotype Control-Pacific Blue (MOPC-21) (3 ul per test) BD Biosciences Cat \#558120 http:// www.bdbiosciences.com/us/reagents/research/antibodies-buffers/immunology-reagents/anti-human-antibodies/cell-surface- 
antigens/pacific-blue-mouse-igg1-isotype-control-mopc-21/p/558120

- Mouse IgG1k Isotype Control-PE (clone MOPC-21) (3ul per test) BD Biosciences Cat \#559320 http://www.bdbiosciences.com/ us/applications/research/intracellular-flow/intracellular-antibodies-and-isotype-controls/anti-human-antibodies/pe-mouse-igg1isotype-control-mopc-21/p/559320

- Mouse IgG1k Isotype Control-APC (clone MOPC-21) (3ul per test) BD Biosciences Cat \#555751 http://www.bdbiosciences.com/ eu/reagents/research/antibodies-buffers/immunology-reagents/anti-human-antibodies/cell-surface-antigens/apc-mouse-igg1isotype-control-mopc-21/p/555751

- Mouse IgG2ak Isotype Control-FITC (clone G155-178) (3ul per test) BD Biosciences Cat \#555573 http://

www.bdbiosciences.com/us/reagents/research/antibodies-buffers/immunology-reagents/anti-human-antibodies/cell-surfaceantigens/fitc-mouse-igg2a-isotype-control-g155-178/p/555573

- Mouse IgG2a Isotype Control-PerCP (clone X39) (3 ul per test) BD Biosciences Cat \#349054 https://www.bdbiosciences.com/ eu/reagents/research/clinical-research---ruo-gmp/single-color-antibodies/percp-mouse-iggsub2asub-kappa-isotype-control-x39/ $\mathrm{p} / 349054$

- Rat IgG2ak Isotype Control-PE-Cy7 (clone R35-95) (3ul per test) BD Biosciences Cat \#557855 http://www.bdbiosciences.com/ us/applications/research/intracellular-flow/intracellular-antibodies-and-isotype-controls/anti-human-antibodies/pe-cy7-ratigg2a-isotype-control-r35-95/p/557855

Immunohistochemistry (IHC)/Immunofluorescence (IF)

- anti-CC10-unconjugated (clone E-11) (IF, 1:500 dilution) Santa Cruz Biotech Cat \#SC-365992 https://www.scbt.com/scbt/ product/cc10-antibody-e-11

- anti-CD3-unconjugated (clone SP7) (IHC, 1:150 dilution) ThermoFisher Cat \#MA1-90582 https://www.thermofisher.com/ antibody/product/CD3e-Antibody-clone-SP7-Monoclonal/MA1-90582

- anti-CD4-unconjugated (clone SP35) (IHC, 1:100 dilution) Genway Biotech Cat \#GWB-B38C3A (product discontinued). Positive control-human tonsil tissue.

- anti-CD8-unconjugated (clone SP16) (IHC, 1:50 dilution) Biocare Medical Cat \#CRM 311 C https://biocare.net/wp-content/ uploads/PDF\%20Data\%20Sheets/311.pdf

- anti-CD11C-unconjugated (clone 5D11) (IHC, 1:100 dilution) Leica Biosystems Cat \#CD11C-563-L-CE https://

www.leicabiosystems.com/ihc-ish-fish/immunohistochemistry-ihc-antibodies-novocastra-reagents/primary-antibodies/products/ cd11c/

- anti-CD20-unconjugated (clone L26) (IHC, 1:100 dilution) Biocare Medical Cat \#CM004C https://biocare.net/product/cd20-

antibody/

- anti-CD34-unconjugated (clone QBEnd10) (IHC, 1:200 dilution; IF, 1:100 dilution) Agilient Cat \#M716501-2 https://

www.agilent.com/store/en_US/Prod-M716501-2/M716501-2

- anti-mCD34-unconjugated (clone MEC 14.7) (IHC, 1:200 dilution) Novus Biologicals Cat \#NB600-1071 https://

www.novusbio.com/products/cd34-antibody-mec-147_nb600-1071

- anti-CD45-unconjugated (clones 2B11 and PD7/26) (IHC, 1:350 dilution) Agilient Cat \#M070101-2 https://www.agilent.com/ store/en_US/Prod-M070101-2/M070101-2

- anti-mCD45-unconjugated (clone 30-F11) (IHC, 1:200 dilution) BD Biosciences Cat \#550539 http://www.bdbiosciences.com/ eu/applications/research/stem-cell-research/cancer-research/human/purified-rat-anti-mouse-cd45-30-f11/p/550539

- anti-CD56-unconjugated (clone 123C3) (IHC, 1:50 dilution) Agilient Cat \#M730429-2 https://www.agilent.com/store/en_US/ Prod-M730429-2/M730429-2

- anti-CD68-unconjugated (clone KP1) (IHC, 1:200 dilution) Agilient Cat \#M081401-2 https://www.agilent.com/store/en_US/ Prod-M081401-2/M081401-2

- anti-Cytokeratin 19-unconjugated (clone EPR1579Y) (IHC, 1:100 dilution) Abcam Cat \#ab76539 https://www.abcam.com/ cytokeratin-19-antibody-epr1579y-ab76539.html

- anti-Cytokeratin 19-unconjugated (clone A53-B/A2) (IF, 1:100 dilution) Abcam Cat \#ab7754 https://www.abcam.com/ cytokeratin-19-antibody-a53-ba2-ab7754.html

- anti-Cytokeratin 19-unconjugated (clone KRT19) (IF, 1:500 dilution) Novus Biologicals Cat \#NB100-687 https://

www.novusbio.com/products/cytokeratin-19-antibody_nb100-687

- anti-mCytokeratin 19-unconjugated (clone EPNCIR127B) (IHC, 1:200 dilution) Abcam Cat \#ab133496 https://www.abcam.com/ cytokeratin-19-antibody-epncir127b-ab133496.html

- anti-Vimentin-unconjugated (clone V9) (IHC, 1:1,000 dilution, IF, 1:250 dilution) Abcam Cat \#ab8069 https://www.abcam.com/ vimentin-antibody-v9-cytoskeleton-marker-ab8069.html

- anti-HCMV Glycoprotein B-unconjugated (rabbit polyclonal) (IF, 1:500 dilution) Sino Biological Cat \#10202-RP01 https://

www.sinobiological.com/CMV-gB-Antibody-g-2881.html

- anti-HCMV IE-unconjugated (clone 6F8.2) (IHC, 1:2,000 dilution) Millipore Cat \#MAB8131 https://www.emdmillipore.com/US/ en/product/Anti-Cytomegalovirus-Antibody-immediate-early-clone-6F8.2,MM_NF-MAB8131

- anti-HCMV IE/E-unconjugated (clones DDG9 and CCH2) (IHC, 1:200 dilution) Cell Marque Cat \#213M-15-ASR http://

www.cellmarque.com/cmsial-ifu/ASR21321030.pdf

- anti-HCMV Late-unconjugated (clone QB1/06) (IHC, 1:50 dilution) Abcam Cat \#ab49211 (product discontinued). Positive control-CMV infected tissue.

- Anti-Zika NS2B-unconjugated (rabbit polyclonal) (IF, 1:50 dilution) GeneTex Cat \#GTX133308 https://www.genetex.com/ Product/Detail/Zika-virus-NS2B-protein-antibody/GTX133308

- anti-MERS-CoV nucleocapsid-unconjugated (rabbit polyclonal) (IF: 1:200 dilution) LS Bio Cat \#LS-C483529 https:// www.Isbio.com/antibodies/mers-coronavirus-nucleocapsid-antibody-elisa-flow-icc-if-immunofluorescence-ihc-ip-wb-western-lsc483529/496447

- anti-RSV-unconjugated (goat polyclonal) (IF, 1:500 dilution) Meridian Life Science Cat \#B65860G https://

meridianlifescience.com/bioSpecs/B65860G.pdf

- anti-RSV-unconjugated (goat polyclonal) (IF, 1:500 dilution) Abcam Cat \#ab20745 https://www.abcam.com/respiratorysyncytial-virus-antibody-ab20745.html

- anti-B-Tubulin IV-unconjugated (clone ONS.1A6) (IF, 1:500 dilution) Sigma-Aldrich Cat \#T7941 https://www.sigmaaldrich.com/ catalog/product/sigma/t7941?lang=en\&region=US

- Anti-Goat IgG heavy and light chains-AlexaFlour ${ }^{\oplus 594}$ (donkey polyclonal) (1:500 dilution) Invitrogen Cat \#A-11058 https:// www.thermofisher.com/antibody/product/Donkey-anti-Goat-IgG-H-L-Cross-Adsorbed-Secondary-Antibody-Polyclonal/A-11058 - Anti-Rabbit IgG heavy and light chains-AlexaFlour ${ }^{\circledR} 488$ (goat polyclonal) (1:500 dilution) Invitrogen Cat \#A-11008 https:// 
www.thermofisher.com/antibody/product/A-11008.html?CID=AFLAG-A-11008

- Anti-Rabbit IgG heavy and light chains-AlexaFlour ${ }^{\circ} 568$ (goat polyclonal) (1:500 dilution) Invitrogen Cat \#A-11036 https:// www.thermofisher.com/antibody/product/Goat-anti-Rabbit-IgG-H-L-Highly-Cross-Adsorbed-Secondary-Antibody-Polyclonal/ A-11036

- Anti-Mouse IgG heavy and light chains-AlexaFlour ${ }^{\circledR} 488$ (goat polyclonal) (1:500 dilution) Invitrogen Cat \#A-11001 https:// www.thermofisher.com/antibody/product/Goat-anti-Mouse-IgG-H-L-Cross-Adsorbed-Secondary-Antibody-Polyclonal/A-11001

- Anti-Mouse IgG heavy and light chains-AlexaFlour ${ }^{\circledR 568}$ (goat polyclonal) (1:500 dilution) Invitrogen Cat \#A-11004 https:// www.thermofisher.com/order/genome-database/details/antibody/A-11004.html?CID=AFLBC-A-11004

- Anti-Mouse IgG heavy and light chains-AlexaFlour ${ }^{\circledR} 488$ (donkey polyclonal) (1:500 dilution) Invitrogen Cat \#A-21202 https:// www.thermofisher.com/antibody/product/Donkey-anti-Mouse-lgG-H-L-Highly-Cross-Adsorbed-Secondary-Antibody-Polyclonal/ A-21202

- Rat IgG2ak Isotype Control-unconjugated (clone KLH/G2a-1-1) (dilution dependent on primary antibody concentration) Novus Biologicals Cat \#NBP1-51104 https://www.novusbio.com/products/igg2a-isotype-control-klh-g2a-1-1_nbp1-51104

- Negative control mouse IgG1k-unconjugated (clone DAK-GO1) (dilution dependent on primary antibody concentration) Agilient Cat \#X093101-2 https://www.agilent.com/store/en US/Prod-X093101-2/X093101-2

- Negative control mouse IgG2ak-unconjugated (clone DAK-GO5) (dilution dependent on primary antibody concentration) Agilient Cat \#X094301-2 https://www.agilent.com/store/en_US/Prod-X094301-2/X094301-2

- Negative control rabbit Ig fraction-unconjugated (rabbit polyclonal Ig) (dilution dependent on primary antibody concentration) Agilient Cat \#X090302-8 https://www.agilent.com/store/en_US/Prod-X090302-8/X090302-8

Validation

The specificity of the antibodies purchased from commercial sources (BD Biosciences, Biolegend, Biorad, Novus Biological, Santa Cruz Biotech, ThermoFisher, Genway Biotech, Biocare Medical, Leica Biosystems, Abcam, Sino Biological, Millipore, Cell Marque, Genetex, LS Bio, Meridian Life Sciences Invitrogen, Agilent, Sigma-Aldrich) were validated by the manufacturer as noted on their website (links provided above for each antibody).

\section{Eukaryotic cell lines}

Policy information about cell lines

Cell line source(s)

Vero CCL-81, MRC-5, and ARPE-19 cells were purchased from ATCC

Authentication

Cell lines were authenticated by morphological identification and virus susceptibility profiles.

Mycoplasma contamination

Cell lines were tested negative for mycoplasma by the supplier.

Commonly misidentified lines

(See ICLAC register)

No commonly misidentified cell lines were used

\section{Animals and other organisms}

Policy information about studies involving animals; ARRIVE guidelines recommended for reporting animal research

Laboratory animals Lung-only mice (LoM) were constructed using 13-18 week old male and female NOD.Cg-Prkdcscid II2rgtm1Wjl/SzJ mice (NSG; The Jackson Laboratory, Bar Harbor, ME) mice. BLT-Lung (BLT-L) mice were constructed using 10-15 week old male and female NSG mice.

Wild animals

The study did not involve wild animals.

Field-collected samples

The study did not involve field-collected samples.

Ethics oversight

Animal studies were carried out according to protocols approved by the Institutional Use and Care Committee at UNC-Chapel Hill and in adherence to the NIH Guide for the Care and Use of Laboratory Animals.

Note that full information on the approval of the study protocol must also be provided in the manuscript.

\section{Flow Cytometry}

Plots

Confirm that:

$\bigotimes$ The axis labels state the marker and fluorochrome used (e.g. CD4-FITC).

Х The axis scales are clearly visible. Include numbers along axes only for bottom left plot of group (a 'group' is an analysis of identical markers).

$\bigotimes$ All plots are contour plots with outliers or pseudocolor plots.

$\bigotimes$ A numerical value for number of cells or percentage (with statistics) is provided.

\section{Methodology}

Sample preparation

Sample preparation for the flow cytometric analysis of peripheral blood and tissues from humanized mice is detailed in the 
Sample preparation

Instrument

Software

Cell population abundance

Gating strategy were gated based on their forward scatter (FSC) and SSC profiles. Gates to define positive and negative populations were defined
For ICS and pentamer staining analyses, we first gated on singlets based on side scatter (SSC) area and height. Cell populations by isotype and fluorescent minus one (FMO) controls when appropriate.

Flow cytometry data was collected on BD LSRFortessa or BD FACSCanto instruments using BD FACSDiva software (version 6.1.3)

Flow cytometry data was analyzed with BDFACSDiva (version 6.1.3) or FlowJo software (version 10)

No cell populations were sorted by flow cytometry.

Tick this box to confirm that a figure exemplifying the gating strategy is provided in the Supplementary Information. 